\title{
MAYBE NEXT MONTH? TEMPERATURE SHOCKS, CLIMATE CHANGE, AND DYNAMIC ADJUSTMENTS IN BIRTH RATES
}

\author{
Alan Barreca \\ Olivier Deschenes \\ Melanie Guldi \\ Working Paper 21681 \\ http://www.nber.org/papers/w21681 \\ NATIONAL BUREAU OF ECONOMIC RESEARCH \\ 1050 Massachusetts Avenue \\ Cambridge, MA 02138 \\ October 2015
}

The authors thank the numerous seminar participants at Oberlin College, Simon Fraser University, Tulane University, University of California-Merced, University of Houston, University of Mississippi, University of Montreal, 2014 IZA Conference on the Labor Market Effects of Environmental Policies, 2014 Southeastern Health Economics Study Group, 2014 Southern Economic Association Meetings, and 2015 Society of Labor Economist Meetings. In addition, special thanks are owed to D. Mark Anderson, Marianne Bitler, Marisa Domino, Daniel Hungerman, Jason Lindo, Elaine Liu, and Nick Sanders for their helpful comments. The views expressed herein are those of the authors and do not necessarily reflect the views of the National Bureau of Economic Research.

NBER working papers are circulated for discussion and comment purposes. They have not been peerreviewed or been subject to the review by the NBER Board of Directors that accompanies official NBER publications.

(C) 2015 by Alan Barreca, Olivier Deschenes, and Melanie Guldi. All rights reserved. Short sections of text, not to exceed two paragraphs, may be quoted without explicit permission provided that full credit, including $(\subset$ notice, is given to the source. 
Maybe Next Month? Temperature Shocks, Climate Change, and Dynamic Adjustments in Birth Rates

Alan Barreca, Olivier Deschenes, and Melanie Guldi

NBER Working Paper No. 21681

October 2015

JEL No. I12,J13,Q54

\begin{abstract}
Dynamic adjustments could be a useful strategy for mitigating the costs of acute environmental shocks when timing is not a strictly binding constraint. To investigate whether such adjustments could apply to fertility, we estimate the effects of temperature shocks on birth rates in the United States between 1931 and 2010. Our innovative approach allows for presumably random variation in the distribution of daily temperatures to affect birth rates up to 24 months into the future. We find that additional days above $80^{\circ} \mathrm{F}$ cause a large decline in birth rates approximately 8 to 10 months later. The initial decline is followed by a partial rebound in births over the next few months implying that populations can mitigate the fertility cost of temperature shocks by shifting conception month. This dynamic adjustment helps explain the observed decline in birth rates during the spring and subsequent increase during the summer. The lack of a full rebound suggests that increased temperatures due to climate change may reduce population growth rates in the coming century. As an added cost, climate change will shift even more births to the summer months when third trimester exposure to dangerously high temperatures increases. Based on our analysis of historical changes in the temperature-fertility relationship, we conclude air conditioning could be used to substantially offset the fertility costs of climate change.
\end{abstract}

\author{
Alan Barreca \\ Department of Economics \\ Tulane University \\ 206 Tilton Hall \\ New Orleans, LA 70118 \\ and NBER \\ abarreca@tulane.edu \\ Olivier Deschenes \\ Department of Economics \\ 2127 North Hall \\ University of California, Santa Barbara \\ Santa Barbara, CA 93106 \\ and NBER \\ olivier@econ.ucsb.edu
}

\author{
Melanie Guldi \\ University of Central Florida \\ Department of Economics \\ 4000 Central Florida Blvd. \\ Orlando, FL 32816-1400 \\ mguldi@bus.ucf.edu
}




\section{Introduction}

All that we can do, is to keep steadily in mind that each organic being is striving to increase at a geometrical ratio; that each at some period of its life, during some season of the year, during each generation or at intervals, has to struggle for life, and to suffer great destruction.

- Charles Darwin, On The Origin of Species (1859)

Some 150 years ago, Charles Darwin posited that environmental changes could impose great costs on fertility. Although there is little consensus how relevant Darwin's hypothesis is for humans in recent years, the strong seasonality in births across countries, including the United States, suggests environmental changes may still play a role. To help disentangle the causal effect of environmental changes from other factors (e.g., holidays), past research has investigated how plausibly random climatic shocks affect fertility (Siever, 1989; Lam and Miron, 1996). While these studies have shown how such shocks can have an immediate effect on conception chances, the extent to which populations can adjust by shifting conceptions to later periods has not been thoroughly investigated. Quantifying the magnitude of this dynamic adjustment is crucial for assessing impacts on total completed fertility, an outcome of policy concern in many developed countries with "below replacement" fertility rates. ${ }^{1}$ Documenting the precise timing of the adjustment also matters for policy since even short-term shifts across months may affect the availability of key resources during formative in utero or postnatal periods and, in turn, impact long-term human capital accumulation. ${ }^{2}$

Our research offers unique insights into this dynamic adjustment by exploring the effects of temperature shocks on monthly birth rates in the United States over an 80-year period (19312010). In addition to relevance for present-day fiscal and public-health policy, quantifying the temperature-fertility relationship is a pressing concern given the large projected increase in global temperatures in the coming century. The broader contribution of our research is to investigate the scope for populations to make dynamic adjustments to mitigate the cost of environmental shocks. Research into this area is limited and generally focuses on extraordinary

\footnotetext{
1 In many developed countries today, total completed fertility rates are currently below 2.1 , which is the rate at which the population "replaces" itself (absent migration). In 2010, total completed fertility rate is estimated at 1.9 in the United States and only 1.7 in high-income countries (World Bank, 2013). These below-replacement rates are a concern for funding of pay-as-you-go pensions, like Social Security (Goss, 2010).

2 Almond and Currie (2011) survey the fetal-origins literature, which provides compelling evidence that earlylife health shocks have consequences for lifelong outcomes. However, the causal relationship between season of birth and long-term outcomes is still unclear (Buckles and Hungerman, 2013).
} 
historical events and natural disasters, ${ }^{3}$ or short-term adjustments in time use across a small number of days. ${ }^{4}$ Relative to existing historical and natural-disaster studies, we focus on less drastic but higher-frequency environmental shocks where the potential for general equilibrium effects, like wage changes, is diminished. Compared to the time-use studies, we test for dynamic adjustments over a longer-time horizon since day-to-day adjustments are complicated by the fact that conception can only occur within a handful of days each reproductive cycle. ${ }^{5}$ The ability of populations to mitigate the costs of an environmental shock in the face of such binding daily constraints is an open empirical question.

While the focus of this study is on the United States, temperature may have a global influence on fertility. Figure 1 plots the log of total births by calendar month for the United States, Germany, and Australia for the years 2000 through 2010 (United Nations Statistics Division, 2014). ${ }^{6}$ Despite Australia having opposite seasons, all three countries exhibit a peak in births somewhere between July and September. However, Australia also experiences a secondary peak in March, during their summer. This seasonal evidence is suggestive of a link between temperature and fertility, though omitted factors, like sunlight and nutrition, complicate causal inference. ${ }^{7}$ As we discuss in Section II, only two older studies (Siever, 1989; Lam and Miron, 1996) document the effects of unusual temperatures on birth rates, thereby controlling for such seasonal confounders. However, the existing studies' models impose strong assumptions on the form of the temperature-fertility relationship and fail to fully account for dynamic adjustments in birth month. As such, the effects of temperature on fertility are still largely unresolved.

We estimate the effects of unusual temperature shocks on birth rates in the United States using state-by-month data spanning 1931 through 2010. To our knowledge, these are the most expansive data ever compiled on temperature and fertility outcomes. Our empirical model has two major innovations over the existing studies (Siever, 1989; Lam and Miron, 1996). First and foremost, we comprehensively test for shifts in conception month, fetal losses, and shortened gestational lengths. To accomplish this, our core empirical model allows temperature

\footnotetext{
3 For example, Hornbeck (2012) studies agriculture's response to the American Dust Bowl, Miguel and Roland (2011) investigate how bombings during the Vietnam War affected long-run economic development, and Smith et al. (2006) explore migration due to Hurricane Andrew.

4 See Connolly (2008) and Graff Zivin and Neidell (2014).

5 Social and biological constraints, such as preferences or age, could also limit cross-cycle adjustments.

6 Birth seasonality is also present in developing countries, though the United Nations data appear to suffer from misreporting in some country-years.

7 For a discussion on some of the hypothesized causes of birth seasonality, see Bronson (1995, 2009), Ellison et al. (2005), Lam and Miron (1991a), Meade and Earickson (2000), and Rodgers and Udry (1988).
} 
to affect birth rates up to 24 months from the time of the shock. Second, we model the temperature-fertility response function with more flexibility to account for non-linear effects or "tipping points". The core variables capture the frequency of daily temperatures that fall in a given 10-degree Fahrenheit $\left({ }^{\circ} \mathrm{F}\right)$ bin with days above $80^{\circ} \mathrm{F}$ as the upper category. This modeling choice is especially important for assessing the potential costs of climate change, which is projected to cause a significant shift in the distribution of daily temperatures.

The evidence indicates hot temperatures lead to a large and statistically significant decline in birth rates 8 to 10 months later. For example, a single additional "hot day" above 80 ${ }^{\circ} \mathrm{F}$, relative to one day between 60 and $70^{\circ} \mathrm{F}$, causes a $0.4 \%$ decrease in birth rates 9 months later (or a reduction of about 1,165 births across the whole United States). After the initial decline, birth rates partially rebound over the next few months; the increase in births in months 11,12 , and 13 offsets about $32 \%$ of the decline in births in months 8,9 , and 10 . We also see a small rebound 19-21 months later, suggestive that some of the affected population is constrained to conceiving in certain calendar months. Contrary to hot days, we find that cold days have little impact on birth rates. As an illustration of long-term adaptation, we document a significant dampening in the temperature-fertility response function beginning in the 1970 s and show that residential access to air conditioning explains about one third of this dampening. Also, states that are more accustomed to higher temperatures are less vulnerable to random fluctuations in hot days.

The estimates show that the dynamic link between temperature and birth rates is a key and understudied determinant of fertility outcomes in the United States. Short-term changes in birth rates will overstate the effect of environmental shocks on long-term birth rates since some of the affected population adjusts by shifting conception month. However, this shift has an added health cost: more births occur the following summer when infant health outcomes are worse. Though the reasons for worse health in the summer are not well established, one channel through which month of birth causally effects infant health might be third trimester exposure to high temperatures (Deschenes et al., 2009). Also, our estimates reveal that temperature could be the single-most important determinant of birth seasonality in the United States. Our dynamic model explains nearly half of the variance in birth seasonality in the United States. Conversely, a model that does not account for the dynamic adjustment can only explain one quarter of the variance.

Finally, our study offers three lessons relevant to climate change policy. First, given we do not observe a full rebound in births in the medium term, we project that climate change could 
exacerbate the already below-replacement birth rates in the United States and other developed countries. Second, we project that climate change could impose a cost on infant health by increasing the proportion of summer births and increasing risk of exposure to even higher temperatures during the third trimester. Third, our analysis of the historical changes in the temperature-fertility relationship indicates that increased access to air conditioning could be used to mitigate these fertility costs. Recent policy discussions around climate change have neglected to mention the potential impacts on fertility. ${ }^{8}$ Furthermore, climate change models generally assume population growth as exogenous. Our work suggests that policy makers and scientists should reconsider fertility as an important and underexplored cost of climate change.

\section{Conceptual framework of the dynamic temperature-fertility relationship}

For a non-pregnant female, the chance of conceiving in any given (reproductive) cycle, henceforth referred to as "conception probability", is a function of her and her male partner's reproductive health and their coital frequency. On the reproductive health side, prior work suggests that exposure to extreme heat negatively affects semen quality and testosterone levels (Levine, 1991; Dada et al., 2001; Chen et al., 2003; Svartberg et al, 2003), and interferes with menstruation, ovulation, and implantation (Meade and Earickson, 2000; Ellison et al., 2005). Temperature shocks may cause fetal losses and preterm births (Lam et al., 1994; Dadvand et al., 2011; Strand et al., 2011). Although a number of experimental studies have shown that high temperatures affect reproduction in animals, the evidence for humans comes mostly from observations on seasonal relationships and could be biased by other seasonal factors. ${ }^{9}$ Also, the seasonal evidence does not indicate whether temperature shocks have an immediate effect on reproductive health and/or a longer-term impact across cycles.

Temperature shocks could also affect conception probabilities via changes in coital frequency during the handful of "fertile days" leading up to and inclusive of the day of ovulation. ${ }^{10}$ For example, extreme heat could raise physiological cost of coitus on a given fertile

\footnotetext{
8 In the 2014 International Panel on Climate Change Synthesis Report (IPCC 2014), there was no mention of fertility costs. Conversely, human mortality is mentioned multiple times.

9 Hansen (2009) provides a summary of the recent experimental research on mammals. Across the studies, the evidence suggests that heat stress impedes fertilization and diminishes the quality of the fertilized embryos. This leads to higher fetal loss and worse health at birth, conditional on surviving to birth. Strand et al. (2011) review the epidemiological literature for humans, which we briefly summarize here.

10 Among a sample of 221 healthy pregnant women intending to become pregnant, Wilcox et al. (1996) found the probability of conception was over 30\% if intercourse occurred on the day of ovulation or up to 2 days before. The probability of conception was closer to $10 \% 3$ to 5 days before ovulation, and nil on other days. Of
} 
day, leading to a shift in coital frequency to some subsequent day(s) when the probability of conception conditional on coitus could be diminished. Alternatively, the behavioral response to a temperature shock could lead individuals to shift coitus to some fertile day(s) in a subsequent cycle. As another channel, temperature may affect time use and, in turn, impact mixing rates among potential sexual partners. ${ }^{11}$ Individuals could be responding to perceived changes in reproductive health due to the temperature shock. Also, individuals may time coitus based on expectations about future weather and their preferences to maximize infant health outcomes or minimize pregnancy costs. ${ }^{12}$ Given our research design, our estimates only incorporate this channel to the extent current temperature shocks affect expectations about future shocks. Like prior research on reproductive health, the best evidence to support a causal link between temperature and coital frequency in humans comes from seasonal relationships, which are potentially biased by omitted factors. ${ }^{13}$

Temperature could also influence fertility through more indirect channels, though the effect on conception probabilities may be delayed. For example, temperature shocks could impact the agricultural sector, which could then affect fertility through delayed impacts on food prices, nutrition, or income. ${ }^{14}$ Using United States data between 1969 and 2011, Deryugina and Hsiang (2014) find that one weekday with temperatures above $86^{\circ} \mathrm{F}$ reduces personal income by about $\$ 20$ per year, the effect operating mostly through labor and crop productivity. In addition, temperature could impact disease transmission, like influenza (Shaman and Kohn, 2009; Barreca and Shimshack, 2012; Lowen and Steel, 2014), which could alter fertility. Given our research design, we cannot definitively differentiate between changes in reproductive health, coital frequency, or the competing indirect mechanisms with the data at hand.

Importantly, any change in conception probabilities in one cycle can affect the number of conceptions in future cycles via changes in the "susceptible population". That is, the population

the successful conceptions, only two thirds actually ended in live births. Fehring et al. (2006) surveyed 141 women between 3 to 13 cycles each and found that, on average, cycles lasted 29 days and ovulation occurred 16 days after the start of the menses.

11 Graff Zivin and Neidell (2014) provide indirect evidence to support this mixing-rate mechanism. Using recent data from the American Time Use Survey, they find that individuals substitute away from outdoor work and outdoor leisure at high temperatures.

12 Using the National Survey of Family Growth, Rodgers and Udry (1988) found that individuals report stopping contraception most often in June and July. If women assume they will conceive right away, these stopping times are consistent with expectations of April and May as the best time to give birth.

13 Albeit in a small sample of women, Udry and Morris (1967) find that coitus dips in August in the United States. For adolescents, sexual debut occurs more often during the summertime, though school vacation complicates attributing this seasonality to temperature (Rodgers, Harris, and Vickers, 1992; Levin, Xu, and Bartkowski, 2003). Levin et al (2003) find a secondary debut in December among romantically linked couples. 14 This mechanism is likely to be more prominent in the earlier time period since agriculture accounts for $21 \%$ of U.S. employment in 1930 but only 4\% in 1970 (Dimitri et al, 2005). 
that failed to conceive in one cycle due to a temperature shock could shift conceptions to a subsequent cycle. More formally, let the temperature shock in cycle $t$ cause conceptions in that cycle to fall by $\Delta_{t}$. In the simple case where the temperature shock has no effect on future conception probabilities and all individuals have identical positive conception probabilities, the change in conceptions in the subsequent cycle $(t+1)$ would be $\Delta_{t} p_{t+1}$, where $p_{t+1}$ is the conception probability in that cycle. The increase in conceptions would be $p_{t+2}\left(1-p_{t+1}\right) \Delta_{t}$ in cycle $t+2, p_{t+3}\left(1-p_{t+2}\right)\left(1-p_{t+1}\right) \Delta_{t}$ in cycle $t+3$, and so on. Given $\Delta_{t}$ and $p_{t^{\prime}}$ (for all $t^{\prime}>t$ ) are positive, we expect an increase (or "rebound") in conceptions in the cycles subsequent to cycle $t$.

If conception probabilities were constant across cycles, conceptions would increase at a decreasing rate after the initial decline in conceptions. The rebound could be non-monotonic in the case of time-varying conception probabilities due to credit constraints or preferences for conceiving in certain calendar months. With constant conception probabilities, the cumulative rebound would asymptotically approach $\Delta_{t} \cdot{ }^{15}$ Conversely, declining reproductive health with age could lead to a smaller cumulative rebound. If the temperature shock has an impact on future conception probabilities $\left(d p_{t+1} \neq 0\right)$, the change in conceptions at $t+1$ would be $\Delta_{t} p_{t+1}+$ $S_{t+1} d p_{t+1}$, where $S_{t+1}$ is the susceptible population and $d p_{t+1}$ is the change in the conception probability due to the temperature shock. For example, the shock could cause lasting health complications $\left(d p_{t+1}<0\right)$ or an increase in coital frequency $\left(d p_{t+1}>0\right)$. Given the sign and magnitude of $d p_{t+1}$ is uncertain, the net effect on conceptions in cycle $t+1$ is ambiguous.

In our study, we use realized births in a given calendar month to quantify the effects of a temperature shock that likely impacted conceptions several months prior. The exact timing will depend on the critical exposure period, the ex ante gestational length, and the time of exposure within the calendar month. This complexity notwithstanding, Table 1 illustrates four key simplified scenarios through which temperature shocks might impact realized births over a 24month period (more details are provided in the Table 1 Note). ${ }^{16}$ In the simplest case (Scenario A), a temperature shock that has an immediate impact on conception probabilities in a given month, henceforth referred to as "exposure month", will reduce births approximately 9 calendar months later followed by a rebound in births in the subsequent months. If some individuals only engage in coitus during one calendar month, the rebound would manifest as an increase in

\footnotetext{
15 With constant conception probabilities, the cumulative rebound in conceptions as of cycle $\mathrm{t}+\mathrm{m}$ would be $\sum_{1}^{m} p(1-p)^{m-1} \Delta_{t}$. At a $p$ equal to $10 \%$, the rebound would be $27 \%$ after 3 months and $72 \%$ after 12 months. 16 We assume the gestational length is 9 months for simplicity. The magnitude of the impact in Table 1 is intended for illustration only. Lam et al. (1994) present a more formal fertility model with illustrative simulations.
} 
births 21 months after the exposure month (Scenario B). A temperature shock could cause preterm delivery and increase births in the exposure month, while reducing births 1 month later (Scenario C). Fetal losses in the first month of pregnancy could manifest as a fall in births at 8 months and a rebound in births beginning at 10 months from the exposure month (Scenario D).

Despite popular interest in this topic, ${ }^{17}$ only a handful of older studies have explored the temperature-fertility relationship using observational data (Siever 1985, 1989; Lam and Miron 1991b, 1996; Lam, Miron and Riley, 1994). Only Siever (1989) and Lam and Miron (1996) (hereafter LM) rely on variation in atypical temperatures thereby controlling for seasonal confounders. Neither of these existing studies thoroughly investigate the importance of dynamic adjustments, which is the key contribution of our work. ${ }^{18}$ Siever (1989) uses data for the United States between 1950 and 1960 and correlates the effect of atypical monthly temperature on the birth rate 9 months later within each state. LM follow a similar approach to Siever, but use data from the United States between 1942 and 1988. LM's core model allows temperature to affect birth rates 9 to 10 months later. Both Siever and LM's models are estimated separately by state, so statistical precision and ability to flexibly control for time-varying cofounders is limited. And, these studies impose relatively strong functional form assumptions on the temperature-fertility relationship: Siever imposes a linear effect in monthly mean temperature, while LM use a quadratic in monthly mean temperature.

\section{Data}

Natality data. Birth counts are available at the state-by-month level from 1931 through 2010. The data come from three sources. We compiled state-by-month birth counts from historical Vital Statistics reports for the year 1931-1967,19 machine-readable Natality Files for the years 1968

\footnotetext{
17 For example, see Slate article "A Time to Be Born: Why do birth rates peak at different times in different places" (Deng, 2014).

18 Although LM note testing for effects at 7, 8, and 11 months, these estimates are statistically insignificant and are dropped from the model. Siever (1989) tests for a rebound in births after month 9 for the period 19501960 , but only a test of joint significance is reported in the text. Siever concludes "the making up effect is essentially complete after 7 months" from a statistical test that fails to reject the null hypothesis (p. 246). The validity of this conclusion is questionable since the confidence interval on this statistical test (not reported) is likely to be large since the model is estimated separately by state and the data only span 11 years.

19 Note that 1931 is the first year that birth counts are available at the state-month level. South Dakota and Texas were not part of the Vital Statistics sample until 1932 and 1933, respectively. Monthly data with finer geographic detail, like county, are not available prior to 1968.
} 
through 2004, ${ }^{20}$ and the CDC's online National Vital Statistics System for the years 2005 through 2010. The monthly birth counts are defined by state of residence except for the 19311941 period, when only state of occurrence is available. ${ }^{21}$ We drop Alaska and Hawaii from the sample since they entered the Vital Statistics sample as states in 1959 and 1960, respectively. We also have state-by-month birth counts by race, although these data are only available starting in 1942.22

We define state-by-month birth rates as the number of births in a given state-month averaged over the days in that month divided by the total state-year population in 100,000 s. $^{23}$ The results are robust to using the female population between 15 and 44 years of age in the denominator or dropping the population denominator altogether. For the years 1931 through 1968, we estimate state-by-year populations by linearly interpolating between Decennial Censuses (Haines 2004). For the years 1969 through 2010, we use state-by-year population estimates from the National Cancer Institute (2013). Our outcome of interest is the log of the birth rate, though our results are robust to using birth rates in levels. Note that the post-1968 Natality data permit an exploration into information found on the birth certificate, like maternal age or birth weight of the infant. However, we present only a cursory analysis of this birth certificate information at the end of the Appendix in the interest of conciseness.

Weather data. The primary weather data come from the National Climatic Data Center's Global Historical Climatological Network (GHCN). The GHCN have daily station information on minimum temperature, maximum temperature, and precipitation. The GHCN data have geographic coverage across the continental United States over our sample period and include an impressive number of weather stations: there were 2,206 stations in 1930 and 4,969 stations in 2010 that consistently report daily weather conditions. ${ }^{24}$

We construct state-by-month weather measures from the station-day observations as follows. First, we aggregate the station-day data to the county-month level using the square of the inverse distance as weights, where we measure distance from the weather station to the county centroid for stations within 100 miles. Next, we average the county-month measures to

\footnotetext{
20 The first year of the Natality data is 1968. In the earlier years, some states' data are $50 \%$ samples, so we weight these births by 2 . The public-use Natality files do not report state of residence after 2004 . Therefore, we relied on CDC's online National Vital Statistics System for the years 2005 through 2010.

21 State of residence is the preferred measure since migration could be endogenous to temperature.

22 New Jersey did not collect birth counts by race in 1962 and 1963.

23 We define "birth rate" in this manner throughout the paper.

24 To address measurement error, we exclude stations for a given year-month if they are missing temperature readings more than 10 days in the year or 2 days in any given calendar month.
} 
the state-month level using county-year population estimates as weights. ${ }^{25}$ Importantly, we create the weather measures at the station-day level before aggregating to the state-month level to preserve non-linear effects.

We have humidity data from a separate data source, the Global Summary of the Day files. We control for specific humidity, which is reported in grams of water vapor per kilogram of air ("g/kg"). The humidity variable has poor coverage prior to 1945 , so we only control for humidity as a robustness check. To the extent that humidity and temperature are naturally correlated, our temperature estimates incorporate some of the effects of humidity. ${ }^{26}$

Summary statistics. Table 2 summarizes the birth rates and key temperature variables for the continental United States and by census region over the entire sample period (1931-2010). These statistics are means calculated using the state-year population as weights. There were approximately 4.7 daily births per 100,000 residents on average during our sample period. ${ }^{27}$ The unweighted annual average for the United States is 3.5 million total live births, ranging from 2.1 million births in 1931 to 4.0 million in 2010. Birth rates are lowest in Northeastern states and highest in Southern states. The average temperature is above $80^{\circ} \mathrm{F}$ approximately 4.7 days per month in the South, compared to only 0.6 days in the Northeast. ${ }^{28}$ Thus, high temperature days and birth rates are positively correlated across regions. However, this positive relationship cannot be used to infer causal effects since many other socioeconomic factors, like poverty rates, also correlate with climate. These omitted variables highlight the importance of using within-state changes in temperature realizations to identify causal impacts.

Seasonality in birth rates varies considerably across region. Panel A of Figure 2 presents the mean of the log birth rate, by census region, over our sample period. In every region, birth rates peak in September suggesting that individuals are most likely to conceive between November and January. Seasonality is greatest in the South, where September birth rates are approximately 15\% higher than April birth rates. The differences across regions also suggest that temperature plays a role in the timing of births, given the South is generally warmer than the rest of the United States. Again, omitted variables hinder our ability to infer causality. Other

\footnotetext{
25 We linearly interpolate county population between the decennial censuses up until 1968. Starting in 1969 , we use county population estimates from SEER.

26 In a study on mortality, Barreca (2012) shows that failing to control for humidity causes little bias on the aggregate, but may be more important for estimating distributional effects across regions.

27 Crude birth rates are typically measured on an annual basis per 1,000 population. We opt for scaling by 100,000 since we are constructing daily births rates at the month level.

28 Note that for station-days with an average temperature above $80^{\circ} \mathrm{F}$, close to $75 \%$ of these station-days have a maximum above $90^{\circ} \mathrm{F}$. Thus we emphasize that a mean daily temperature above $80^{\circ} \mathrm{F}$ is very hot.
} 
seasonal factors, like demand for agricultural labor, could also account for cross-region differences in birth seasonality. Our empirical model mitigates this type of concern by including state-by-calendar-month fixed effects.

Panel B of Figure 2 indicates the seasonality in birth rates declined significantly over time. As a simple illustration, we break our sample into two time periods: 1931-1969 and 1970-2010. During the 1931-1969 period, the birth rate was approximately 12\% higher in September than in April. The difference between September and April birth rates was closer to 9\% during the latter period. This suggests the temperature-fertility relationship dampened significantly over time, something we estimate more formally below.

\section{Methodology}

To identify the effect of temperature fluctuations on the birth rate, our model relies on plausibly random variation in the temperature distribution for a given state and calendar month. To begin, we estimate the following panel regression model that follows the specification of Barreca (2012) and Barreca et al. (forthcoming) who analyze similar vital statistics data:

(1) $Y_{s t}=\sum_{j}^{J} \sum_{k}^{K} \beta_{k}^{j} T E M P_{s, t-k}^{j}+\sum_{k}^{K} \gamma_{k} X_{s, t-k}+\alpha_{s m}+\delta_{t}+\theta_{s y}+\pi_{s m}^{1} * t+\pi_{s m}^{2} * t^{2}+e_{s t}$

where $Y$ is the $\log$ of the birth rate in state $s$ at year-month $t . X$ is a vector of precipitation controls. ${ }^{29} \alpha_{s m}$ is a state-by-calendar-month fixed effect to help ensure our model is identified from the presumed random annual fluctuation in the distribution of temperatures in a given state and calendar month. These fixed effects adjust for permanent unobserved state-by-month determinants of the birth rate, such as seasonal employment. Year-by-calendar-month fixed effects $\left(\delta_{t}\right)$ control for time-varying factors that are common to all states, like national business cycles. State-by-calendar-month quadratic time trends $\left(\Pi_{s m}\right)$ help mitigate potential biases from convergence in seasonality across states over time. State-by-year fixed effects ( $\left.\theta_{\text {sy }}\right)$ help account for temperature changes that correlate spuriously over time with demographic changes at the state level, such as immigration. We cluster standard errors at the state level to allow for serial

\footnotetext{
29 We control for the fraction of days in the month $t-k$ with between 0.01 and 0.50 inches and above 0.50 inches. The omitted category is the fraction of the month with no precipitation.
} 
correlation in the errors. We weight by state-year population in the preceding year $(y-1)$ to improve precision and avoid endogenous weights.

TEMP is a vector of $\mathrm{J}$ temperature bins that captures the distribution of daily average temperatures in state $s$ in month $t-k$. The bins represent the fraction of each month when daily mean temperatures are $<30,30-40,40-50,50-60,70-80,>80^{\circ} \mathrm{F}$, with $60-70^{\circ} \mathrm{F}$ as the omitted category. This type of specification is now common in studies examining temperature effects (Dell et al., 2014). The possibility of a dynamic relationship between birth rates and temperatures is introduced by allowing birth rates in month to be affected by the temperature bins for up to 24 months inclusive of month $t$ (denoted by the index $k=0,1,2, \ldots, 23$ ). We also estimate the impact of temperatures on births 1 to 3 months prior (denoted by the index $k=-3$, $2,-1)$ as a placebo check since these temperatures were realized after delivery and should not affect prior birth rates. In sum, we have six temperature variables estimated over 27 months ( 3 placebo months +24 treatment months). In the interest of conciseness, the figures and tables that follow will either report: a) the coefficients for a single average temperature category (e.g., above $80^{\circ} \mathrm{F}$ ) across all 27 exposure months, or b) the coefficients for a single exposure month across the six temperature bins.

As a robustness check, we also test for impacts using a polynomial spline in the daily mean temperature, with knots at $10,30,50,70$, and $90^{\circ} \mathrm{F}$. We also estimate one model where the upper temperature bin is $90^{\circ} \mathrm{F}$, and one where the lower bin is $20^{\circ} \mathrm{F}$. We use diurnal temperatures in place of daily mean temperatures as a test of intra-day temperature extremes. For example, a day with a maximum of 90 and a minimum of 80 might affect fertility outcomes differently than a day where the maximum was 100 and the minimum was 70 , despite both having the same daily mean temperature. ${ }^{30}$ We also include a set of humidity controls in one specification check.

\section{Results}

Core results. Figure 3 reports the effects of one $>80^{\circ} \mathrm{F}$ day (relative to one day in the $60-70{ }^{\circ} \mathrm{F}$ temperature bin) on the log birth rate across the full set of exposure months (e.g., the month of birth, the preceding 23 months, and 3 future placebo months) using our core empirical model (equation 1). We control for the full set of temperature bins, though we focus on the effects of $>80^{\circ} \mathrm{F}$ days here. The estimates indicate each additional $>80^{\circ} \mathrm{F}$ day causes birth rates to fall

\footnotetext{
30 We linearly interpolate diurnal temperature using the daily maximum and minimum.
} 
by approximately $0.06 \% 8$ months later, $0.39 \% 9$ months later, and $0.21 \% 10$ months later, all statistically significant at the five-percent level. Using the average (unweighted) number of monthly births over our sample period (295,000), the effect size at 9 months implies a reduction of 1,165 fewer births across the whole United States in that one month. The fact that the largest effect is observed at 9 months is consistent with hot days having an immediate impact on reproductive health and/or coital frequency around the time when conception would have occurred.

The effect at 8 months could also be explained by exposure around the time of conception given a typical distribution of gestational lengths. For example, the magnitude at 8 months relative to 9 months is fairly in line with the distribution of gestational lengths observed in the Natality data between 2000 and 2004. Specifically, 15\% of births have a gestational length of 8 calendar months and $68 \%$ have a gestational length of 9 calendar months, or a ratio of one-to-five, which is similar to the relative magnitudes of our estimates $(0.0006 / 0.0039 \approx$ 1/6). However, we cannot rule out the possibility that the reduction in births at month 8 was due to miscarriage in the first month after conception among pregnancies that would have lasted approximately 9 months.

The relative effect size in month 10 is not consistent with the critical exposure period occurring around the time of conception all else equal. Given about 15\% of births span 10 calendar months, we would also expect the coefficient at 10 months to be about one fifth the magnitude at 9 months. ${ }^{31}$ Instead, the coefficient is about half the magnitude $(0.0021 / 0.0039$ $\approx 1 / 2$ ). There are two plausible explanations for the effect size at 10 months. First, the fall in births were made up disproportionately of individuals who have longer gestational lengths. ${ }^{32}$ Second, and untestable with the data at hand, exposure to high temperatures reduces conception probabilities for up to two months. For example, heat-related morbidity may diminish reproductive health for up to two cycles.

We document a sizable "rebound" in births at 11, 12, and 13 months after the temperature shock. For example, one $>80^{\circ} \mathrm{F}$ day causes a $0.10 \%$ increase in births 12 months later. Note the cumulative effect of a temperature shock over months 8-10 is a decrease of $0.0066 \log$ points, while births rebound by 0.0021 log points over months 11-13 (jointly

\footnotetext{
31 If some of the reduced births in month 8 and 9 were then displaced into month 10 , then the expected magnitude at month 10 would be even smaller.

32 We present a cursory test of this hypothesis in Appendix B by examining the probability of "first live birth", which typically implies a longer gestational length. Between 2000 and 2004, 17\% of first (live) births had gestations of 10 calendar months compared to $13 \%$ among higher-order births. The direction of the effect is consistent with this hypothesis, though the estimate is statistically insignificant.
} 
statistically significant) and an additional 0.0012 log points over months 14-23 (jointly statistically significant). As such, the rebound in months $11-13$ offsets $32 \%(0.0021 / 0.0066)$ of the decline in months 8-10, and months $14-23$ offset an additional 18\% (0.0012/0.0066), bringing the cumulative rebound to $50 \%$. Note that the majority of the secondary rebound (0.0008 log points) occurs between months 19-21 (jointly statistically significant), suggesting a segment of the population may be credit constrained or have preferences for conceiving in certain calendar months.

We also find evidence that temperature shocks reduce gestational lengths by approximately one month. One $>80^{\circ} \mathrm{F}$ day causes a statistically significant $0.03 \%$ increase in birth rates in the exposure month (month 0 ) and a $0.06 \%$ decrease one month later (month 1 ). The larger magnitude of the month 1 coefficient is suggestive that temperature shocks may cause fetal deaths near the end of some pregnancies. However, we cannot reject the possibility that the coefficients at month 0 and month 1 are equal in absolute value $(p=0.166) .{ }^{33}$ Importantly, our estimates for the placebo months $(-3,-2,-1)$ are statistically insignificant and near zero. Thus, our model appears to be free of biases from spurious time trends.

Figure 4 Panel A presents the temperature-fertility response function linking birth rates in month $\mathrm{t}$ with daily temperatures in month $\mathrm{t}-9$ to explore the effects of colder temperatures. Though we focus on the effects at 9 months here, we control for the full set of exposure months. Identical by design to Figure 3, we observe a large and statistically significant decrease in birth rates from exposure to one $>80^{\circ} \mathrm{F}$ day. Each $70-80^{\circ} \mathrm{F}$ day also reduces birth rates 9 months later, but to a lesser degree than $>80{ }^{\circ} \mathrm{F}(0.14 \%$ vs. $0.39 \%)$. Colder temperatures below the omitted $60-70^{\circ} \mathrm{F}$ category have little impact on birth rates 9 months later. The effect of $<30^{\circ} \mathrm{F}$ in other exposure months is also minimal (see Appendix Figure A2).

Figure 4 Panel B illustrates the importance of accounting for non-linear effects in the temperature-fertility relationship. We compare our core model estimates to estimates from a model with identical controls but with a quadratic in monthly mean temperatures in place of daily temperature bins, similar to previous research. The comparison is not so straightforward since the marginal effect of a one-day change in temperature is conditional on the monthly mean temperature in the quadratic monthly model. ${ }^{34}$ Nonetheless, the quadratic monthly model

\footnotetext{
33 In Appendix Section B, we test for reduced gestational lengths using post-1968 Natality data; the sign of the coefficients provide support, but the estimates are statistically insignificant.

34 The marginal effect (dy) of a one day change in the temperature ( $d t)$ in a quadratic model with monthly average temperature $\left(y=\beta_{1} T+\beta_{2} T^{2}\right)$ is $d y / d t=\beta_{1} d T / d t+2 \beta_{2} T d T / d t$, where $T$ is the average monthly temperature. Comparison with existing studies (Siever 1989 and LM) is also complicated by the fact their
} 
shows that a monthly mean shift in temperatures from 65 to $85^{\circ} \mathrm{F}$ would result in a $7 \%$ decline in births 9 months later. Conversely, our binned model implies 30 additional days at $85^{\circ} \mathrm{F}$ would result in a $12 \%$ decline in births. The quadratic model finds that colder temperatures cause higher birth rates, while the binned model indicates that temperatures below $70^{\circ} \mathrm{F}$ have no effect on birth rates. In other words, the quadratic representation of temperature, used in earlier work, understates the effect of high temperatures and overstates the effect of cold temperatures due to failure to capture a tipping point around $70^{\circ} \mathrm{F}$.

Robustness Checks. The main results in Figures 3 and 4 are robust to different model specifications, as shown in Appendix Figures A3 - A8. We show estimates using birth rates in levels and using the population of women 15-44 as the denominator in our birth rate measure (Appendix Figure A3). We set the upper temperature bin at $90^{\circ} \mathrm{F}$ in one model, and below $20^{\circ} \mathrm{F}$ in another (Appendix Figures A4 and A5). We find similar effects using diurnal temperature bins that captures the frequency of time (not days) within a given $10^{\circ} \mathrm{F}$ bin, with temperatures above $90{ }^{\circ} \mathrm{F}$ and below $0{ }^{\circ} \mathrm{F}$ as the categories at the bounds (Appendix Figure A6). We show the estimates using a spline in daily mean temperature (Appendix Figure A7). The spline model estimates are quite similar to the binned model. However, the spline predicts larger effects at temperatures past $85^{\circ} \mathrm{F}$, a point we consider in our discussion on climate change below.

We estimate the effects of temperatures and humidity in Appendix Figure A8. One "high humidity day" above 18 grams of water vapor per kilogram of air (g/kg) leads to $0.2 \%$ decrease in births 9 and 10 months later. ${ }^{35}$ The estimated effects of hot temperatures are slightly diminished (relative to Figure 3), suggesting that humidity is one natural mechanism through which temperature impacts birth rates. For example, the inclusion of humidity causes the effect at month 9 to decline from $0.4 \%$ to below $0.3 \%$. Like cold temperatures, low humidity levels are not a strong predictor of birth rates (results not reported). Given the positive association between influenza and low humidity levels (Shaman and Kohn, 2009; Barreca and Shimshack, 2012), we can rule out influenza as one of the primary mechanisms.

While the qualitative dynamic relationship is robust to varying the fixed effects, the levels of the estimates are sensitive to such modifications. Recall that our core model includes year-

models are estimated separately for each state and race. For example, for whites in Georgia, LM's estimates imply that a one-day increase in temperature from 65 to $85^{\circ} \mathrm{F}$, in a month with mean temperatures of $65^{\circ} \mathrm{F}$, would reduce birth rates 9 months later by $0.17 \%$, which is smaller in magnitude than what we estimate.

35 We model humidity using $2 \mathrm{~g} / \mathrm{kg}$ bins with $8-10 \mathrm{~g} / \mathrm{kg}$ as the omitted category, $0-2 \mathrm{~g} / \mathrm{kg}$ as the lowest bin, and above $18 \mathrm{~g} / \mathrm{kg}$ as the upper bin. Note the average state experiences 3 days per year above $18 \mathrm{~g} / \mathrm{kg}$. 
month fixed effects, state-by-calendar-month fixed effects, state-by-calendar month quadratic time trends, and state-by-year fixed effects. Appendix Figure A9 presents the estimates from a model with identical controls to our core model, but excludes the state-by-year fixed effects. The estimates present a similar dynamic relationship, with births falling 8-10 months later, followed by a rebound over the next few months. However, this model's estimates are systematically shifted in the negative direction including the placebo months $(-3,-2$, and -1$)$ where the weather realization occurred after the birth month. This suggests a spurious time series correlation between temperatures and birth rates. An examination of the regional trends supports this assertion (see Appendix Figure A1). ${ }^{36}$ For this reason, we opt for the model with state-year fixed effects as our preferred specification.

One concern is that the identifying variation in our model is coming almost entirely from a select group of states. As a simple check on this concern, we regress the variable for $>80^{\circ} \mathrm{F}$ days on the full set of controls in our model with the exception of precipitation or other temperature variables. For each state, we examine the annual average of the absolute residuals from this regression for the full sample period (1931-2010). As illustrated in Appendix Figure A10, Southern states expectedly account for more of the residual variation. However, the difference is not overwhelming: Northeastern states have average residuals roughly one fourth to one half the magnitude of Southern states.

Explaining the seasonality in births. The dynamic effect of temperature has an important influence on seasonal birth rates. As one illustration, we take our core model estimates (Figure 3 Panel B) and apply them to the observed distribution of temperatures over our sample period. Figure 5 Panel A illustrates the predicted values follow a nearly identical pattern, with births at a trough in April and a peak in August. The model underestimates birth rates in September and overestimate births in October through January, which may be partially explained by the December holidays causing a forward displacement in conceptions. ${ }^{37}$ That said, the model still explains nearly half of the variance $\left(R^{2}=0.46\right)$ when correlating the predicted points to the actual points in Panel A. Note that a substantial portion of the goodness of fit comes from accounting for the rebound in births. Specifically, when we include only months 9 and 10 in our

\footnotetext{
${ }^{36}$ As illustrated in Appendix Figure 1, the fraction of days above $80^{\circ} \mathrm{F}$ increases substantially in the Southern United States after 1970. Conversely, birth rates are falling relatively faster in the South after 1970.

37 Factors that are fixed across seasons, such as holidays, disease, nutrition, and expectations about the weather most likely contribute to the seasonal birth patterns observed in the United States. However, these fixed factors are controlled for in our model, so they do not pose a threat to our identification strategy. Rather, they are other important determinants that account for the unexplained variance in seasonality.
} 
model, similar to past research, the $\mathrm{R}^{2}$ for the predicted-actual comparison falls to $0.23 .^{38}$ The spline model predictions (not reported) are nearly identical to our core estimates.

The model also predicts substantially more seasonal variability in the South relative to the rest of the United States. Figure 5 Panel B plots the predicted variation in log birth rates around June. Our estimates imply a 13\% predicted difference in births between April and August for the South. Conversely, there is only an $8 \%$ difference for the Northeast, a $9 \%$ difference for the Midwest, and only a $6 \%$ difference for the West. The pattern is qualitatively similar to the cross-region differences in seasonality observed (see Figure 2 Panel B). These seasonal differences suggest that climatic factors may impose a greater fertility cost on the South, which could add to our understanding of historical differences across regions.

Implications for infant health. Part of the fertility response from exposure to extreme heat in the summer is a shift in births from the spring to the following summer, when infant health outcomes are generally worse. For example, low birth weight risk is 0.003 percentage points higher in August than in March (Appendix Figure A11). The causal mechanisms underlying this relationship are not well established given concerns over maternal selection (Buckles and Hungerman, 2013; Currie and Schwandt, 2013). However, results from Deschenes et al. (2009) suggest that exposure to hot days in the third trimester may be responsible. As a stylized example, we quantify the impact of a shift in birth month on infant health assuming the effect operates exclusively through exposure to more $>80^{\circ} \mathrm{F}$ days during the "presumed third trimester", which we define as the three months prior to the month of birth inclusive.

For this calculation, we first estimate the effects of temperature on the probability of low birth weight $(<2,500$ grams), a commonly used indicator of poor in utero health, using Natality data (1968-2010). As we discuss more formally in Appendix Section B, these estimates come from a model with a smaller set of exposure months (0-13), but is otherwise identical to equation (1). In brief, we find that exposure to each $>80^{\circ} \mathrm{F}$ day leads to a statistically significant increase in the risk of low birth weight by 0.009 percentage points in the month of birth, 0.002 percentage points 1 month prior to the month of birth, and no effect 2 months prior. To determine low birth weight risk by calendar month, we combine these three estimates with the average monthly distribution of $>80^{\circ} \mathrm{F}$ days over the 1968-2010 period (see Appendix Figure A11). For example, a shift in birth month from April to August exposes infants to 23 more days with temperatures $>80^{\circ} \mathrm{F}$ in the presumed third trimester (June, July, and August). Finally, we

38 The $\mathrm{R}^{2}$ is 0.44 in a model that has quadratic in monthly mean temperature for the full set of months. 
predict how temperature-induced seasonality in births (Figure 3) would affect low birth weight risk relative to no seasonality. This calculation implies a 0.05 percentage point increase in low birth weight risk, or $0.7 \%$ relative to the average low birth weight risk of $7.4 \%$. In sum, not only do high temperatures adversely affect realized births, but any dynamic adjustment to mitigate this fertility cost is potentially offset by worse infant health outcomes.

\section{Heterogeneity in impacts}

Next, we restrict the model to exposure months 0 through 13 in order to improve statistical power and facilitate exposition of the results. All other controls are identical to our core model (equation 1). We focus on the effects of days above $>80^{\circ} \mathrm{F}$, though our model controls for other temperature bins. Table 3 Panel A illustrates that the main estimates on $>80^{\circ} \mathrm{F}$ days in months 8 through 13 are unchanged using the narrower set of exposure months. Below, we explore how the effect of $>80^{\circ} \mathrm{F}$ days vary by time period, climate, and race with this parsimonious model.

Heterogeneity over time. We first test for differences in the temperature-fertility response function by time period. Table 3 (Panel B) revisits the effects of each $>80^{\circ} \mathrm{F}$ day by exposure month between the 1931-1969 and 1970-2010 periods. Here, we use the full set of years in our sample, but interact our temperature variables with an indicator for the time period. The estimates for months 9 through 13 are much smaller in the later period, with the differences being statistically significant. For example, the effect of one $>80^{\circ} \mathrm{F}$ day on birth rates 9 months later falls by roughly half, from $0.57 \%$ to $0.31 \%$, over this time period.

Figure 6 further investigates the changes over time by documenting the temperaturefertility relationship by decade. Here, we interact each temperature bin with an indicator for each decade. We only present the marginal effects of each additional $>80^{\circ} \mathrm{F}$ day on log birth rates 9 months later, though we include the full set of temperature bins across exposure months 0-13. In the 1940s, 1950s, and 1960s, exposure to one additional $>80^{\circ} \mathrm{F}$ day consistently causes a $0.6 \%$ reduction in the birth rate 9 months later. The effect sizes monotonically decrease after the 1960s. By the 2000s, the effect size is less than half: one additional $>80^{\circ} \mathrm{F}$ day causes the birth rate 9 months later to decline by only $0.2 \%$. Interestingly, the effects of $>80{ }^{\circ} \mathrm{F}$ day are relatively smaller in the 1930s than in the 1940s, 1950s, or 1960s.

This dampening of the temperature-fertility relationship follows the changes in the temperature-mortality relationship over the same time period. Barreca et al. (forthcoming) show 
that the diffusion of residential air conditioning can explain almost all of the changes in the temperature-mortality relationship in the pre-1960 and post-1960 periods. We test the hypothesis that residential air conditioning also explains changes in the temperature-fertility relationship in section VIII below.

Heterogeneity by climate. To investigate the role of adaptation in response to long-term average temperatures, we split our sample of states in half based on each state's average exposure to days above $80^{\circ} \mathrm{F}$. Table 3 Panel $\mathrm{C}$ shows the magnitude of the effects in months 8 through 10 are all smaller in states with warmer climates. The difference between 'cold' and 'hot' states at 9 months is important: one $>80^{\circ} \mathrm{F}$ day causes a $0.37 \%$ decrease in births in hot states versus a $0.55 \%$ decline in cold states, corresponding to a $49 \%$ relative (statistically significant) difference in the magnitude of the coefficients. Similarly, the hot-cold state differences in the coefficients at 8 and 10 months correspond to gaps of $118 \%$ and $66 \%$, respectively. These results suggest that long-term adaptation, as embodied by differential historical exposure to high temperature days, plays a role in mitigating the effects of high temperatures. However, we cannot rule out the possibility that another unobserved factor, like wealth, accounts for some of the heterogeneity across hot and cold states.

Heterogeneity by race. We explore differential impacts by maternal race in Table 3 Panel D as a cursory test whether the temperature-fertility relationship varies by socioeconomic status. Due to data limitations, the by-race analysis begins in 1942 . While the estimates for non-whites are larger in absolute value, the differences in coefficients are statistically insignificant in all months but month 12. The evidence indicates that the temperature-fertility relationship does not substantially differ across racial groups, though statistical precision is a limiting factor. In Appendix Section B, we further test for the role of socioeconomic status by analyzing parental information on the birth certificate, such as maternal age and education, for the years 19682010. The estimated relationships between hot days and birth-certificate characteristics suggest that mothers with lower socioeconomic status are only slightly more vulnerable to hot days. ${ }^{39}$ See Appendix Section B for more detail.

\footnotetext{
39 Our findings are different from, but not necessarily in conflict with, Buckles and Hungerman (2013). They find that weather conditions at birth are a strong predictor of seasonality in maternal characteristics. However, Buckles and Hungerman's estimates are partially identified from fixed differences in seasonality and, unlike our study, incorporate expectations about the weather.
} 


\section{Air conditioning and the temperature-fertility relationship over time}

As noted above, there was a substantial decline in the temperature-fertility relationship starting in the 1970s. Here, we restrict our sample to the 1960-2010 period and explore whether residential air conditioning $(\mathrm{AC})$ can explain this decline using the approach of Barreca et al. (forthcoming). Our measure of AC coverage by state of residence is linearly interpolated between the 1960, 1970, and 1980 Decennial Censuses. ${ }^{40}$ We use the growth rate in AC coverage between 1970 and 1980 to project out to 2010, while capping the coverage at $100 \% .{ }^{41}$ Our work builds on Siever (1989), which correlated changes in air conditioning between 1960 and 1980 with changes in birth seasonality. We extend Siever's work by correlating changes in the temperature-fertility response function explicitly, allowing us to include state-by-month time trends to mitigate possibly spurious trends in birth seasonality across states that are correlated with $\mathrm{AC}$ adoption.

Note that we take two steps to account for the possibility that the adoption of air conditioning is correlated with time-varying omitted factors that may also impact birth rates, such as changes in wealth. First, and already present in our core model, we control for state-year fixed effects to account for those factors that correlate with our state-year AC measure, but are independent of month of year. Second, we control for the interaction between the temperature variables and a linear time trend to mitigate concerns that the trend in air conditioning coverage correlates with secular trends in vulnerability to temperature extremes.

We find that the diffusion of air conditioning substantially mitigated the temperaturefertility response function, especially the effect of high temperatures. Figure 7 Panel A presents the main effect of temperature and Panel B the interaction with AC coverage on births 9 months later. The coefficient on the air conditioning interaction with $>80^{\circ} \mathrm{F}$ temperature-days is statistically significant and large $(0.0025 \log$ points) relative to the main effect $(0.0068 \log$ points). Importantly, the interaction between temperature and AC is small and statistically insignificant at colder temperatures, further supporting the presumed temperature control mechanism provided by AC.

Table 4 Panel A presents the $\mathrm{AC}$ interaction terms on the $>80^{\circ} \mathrm{F}$ variables for the full set of months (0-13). Positive and statistically significant AC coefficients at 8 , 9, or 10 months

\footnotetext{
40 We define "air conditioning" as at least one air conditioning unit or central air conditioning.

${ }^{41}$ Appendix Figure A12 illustrates the estimated AC coverage by region. Assuming classical measurement error, we expect the estimates to be biased downward. Additionally, clustering the standard errors at the state level helps mitigate concerns about the interpolation generating serially correlated errors.
} 
would imply that AC mitigates temperature's influence around the time of conception. Indeed, the effect on the $A C$ interaction term is positive at 8,9 , and 10 months, though only months 9 and 10 are statistically significant. The negative coefficient on the interaction at 12 and 13 months suggests that air conditioning also mitigates the rebound in births, or reduces the impact on women who are likely to conceive right after a temperature shock, though only month 12 is statistically significant.

Next, Table 4 Panel B adds controls for other interactions with factors that may have contributed to historical changes in the effects of high temperature on birth rates. Specifically, we add temperature interactions with state-year measures for the fraction of women with high school degrees (or more education), access to legal abortion, and unmarried women's legal access to the birth control pill before age 21 (Bailey, 2006; Goldin, 2006; Goldin and Katz, 2002; Guldi, 2008; Levin, Kane, Staiger, Zimmerman, 1996). ${ }^{42}$ One concern is that these factors were changing in the early 1970 s at the same time as residential AC diffusion rates expanded, and could act as omitted variable in the simple interaction regression of Panel $A$. After accounting for these additional factors in Panel $B$, the coefficient on the AC interaction is still statistically significant and only slightly diminished (0.00194 vs. 0.00252$)$. The interaction coefficients on these other variables are generally small and statistically insignificant. Although we do not find evidence that these factors were important contributors to the dampening of the temperature-fertility relationship, our findings do not refute their role in the dramatic decline in birth rates that began in the late 1950s.

To demonstrate the magnitude of the AC estimates, we note that the diffusion of AC can account for about one third of the change in the temperature-fertility relationship between 1960 and 2010. As noted above in Figure 6, the effect of one $>80^{\circ} \mathrm{F}$ day on birth rates 9 months later fell from $0.006 \mathrm{log}$ points in the 1960 s to about $0.002 \mathrm{log}$ points by the 2000 s. The estimated AC coverage increased from $21 \%$ in the 1960 s to $87 \%$ in the 2000 s. As such, the change in AC causes the effect to fall by 0.0017 log points ([0.87-0.21] x 0.0025 log points), or about one third of the 0.0043 log point decline. As another thought experiment, our estimates

\footnotetext{
42 We focus on variation in the legal access to the "Pill" to unmarried women under 21 because it occurred in the 1970s. Married women gained legal access to the Pill in the early-to-mid 1960s (Bailey, 2010). The visible dampening of the temperature-fertility relationship began in the 1970s (Figure 4), so the introduction of the Pill in 1960 is not likely to be an important omitted variable, though utilization could be changing over this time.
} 
imply that the diffusion of residential air conditioning reduced the number of displaced births from exposure to $>80^{\circ} \mathrm{F}$ days by about 25,000 per year between 2000 and 2010.43

\section{Climate change projections}

To quantify the potential impact of climate change on birth rates, we combine our temperaturefertility estimates with end of the century (2070-2099) climate projections from the Hadley CM3 model. We use the A1FI "business as usual" scenario, which assumes no concerted reduction in greenhouse gas emissions. Note that by using only one set of climate projections, our calculations abstract from uncertainty in the climate model themselves and, therefore, should be considered as illustrative of the potential magnitude. A more detailed analysis of uncertainty would incorporate additional projections from other climate models (see e.g., Burke et al., 2015). The unit of observation in the Hadley data is day by grid point, where grid points are spaced out every 2.5 degrees latitude and 2.5 degrees longitude. ${ }^{44}$ The main variables include minimum temperature, maximum temperature, and precipitation. We aggregate the Hadley data to the county level using inverse distance weights squared for the nearest four grid points. Then, we aggregate data up to the state level using county population in 2000 as weights. Finally, we adjust projections to account for the fact that the Hadley model predicted warmer weather than actually realized during the earlier years of the model run (1990-2002).

Appendix Figure A13 Panel A illustrates the projected changes in the distribution of daily temperatures between the 1990-2002 period and the $2070-2099$ period. ${ }^{45}$ In short, the Hadley CM3 model projects a substantial increase in the frequency of hot days. For example, there will be 64 more days per year with $>80^{\circ} \mathrm{F}$ days on a baseline of 31 days. Not surprisingly, the increase in $>80^{\circ} \mathrm{F}$ days occurs mostly between May and September (Appendix Figure A13 Panel B); June, July, and August will each experience at least 10 more $>80^{\circ} \mathrm{F}$ days.

To make projections regarding the impact of climate change, we take our core temperature-fertility estimates and apply them to the distribution of temperature changes predicted by the Hadley model. These projections are likely to overstate the negative impacts of

\footnotetext{
43 There are about 33 days per year with mean temperatures above $80^{\circ} \mathrm{F}$ between 2000 and 2010 and about 342 thousand births per month on average. So, the calculation is (1-(exp(33 days $\times 87 \%$ with AC $\times 0.0025$ coefficient)) $\times 342,000$ births $\approx 25,000$. The affected births may have been displaced to other months or avoided all together, something we cannot definitively determine given the precision of our estimates.

44 Degrees vary in distance depending on the latitude. For example, a 2.5-degree change in latitude (longitude) is roughly 150 (111) miles around Chicago and 170 (130) miles around New Orleans.

45 We use the 1990-2002 time period as the baseline since the climate model data begin in 1990. And, we do not have access to data after 2002 since the data are no longer publicly accessible.
} 
climate change on completed fertility. Our empirical model is identified by monthly shocks to the temperature distribution in each state, which discounts the possibility that people adjust expectations about the frequency of future climatic shocks and make adaptive investments accordingly. Relatedly, the calculations assume the size and geographical distribution of the population remains at year 2000 levels, which ignores the possibility of migration or our own observation that population is endogenous to temperature. We rely on the more parsimonious model with exposure limited to months 0 through 13 to improve statistical precision. As such, our projections ignore any longer-term rebound that occurs after month 13.

Table 5 row A presents the projected impacts on birth rates for the continental United States during the 2070-2099 time period using our post-1970 model estimates from Table 3 Panel B. The table decomposes the projected changes in annual birth rates due to exposure to days above and below $70^{\circ} \mathrm{F}$, respectively, as well by categories of exposure months (months 07, months 8-10, and months 11-13). Column (4a) reports the impact of the full distribution of temperature changes on the annual birth rate. Column (4b) incorporates the effects of rainfall changes using the parameters from our model. The table reports the log change in annual birth rates across columns (1a) through (4b). Column (4c) translates the effect into the number of births assuming 4 million births per year, which is the average in the 2000s.

In short, we project that annual birth rates will decline by a statistically significant $2.6 \%$ (column 4b), or about 107,000 fewer births per year (column 4c). About one quarter of the effect of high temperature exposure will be offset by a shift in birth month: Days above $70^{\circ} \mathrm{F}$ cause a 0.028 log points decline in birth rates 8 to 10 months later (column 2b), but then birth rates rebound by 0.006 log points in months 11 to 13 (column 3b). Using the same parameter estimates, Rows B through E show similar effects on birth rates in the Northeast (3.2\%), Midwest (2.8\%), and South (2.8\%), but smaller impacts in the West (2.2\%).

Row $F$ projects the change in birth rate for the entire United States using a pared down model that only accounts for exposure in months 9 and 10 only. By failing to account for the rebound in months 11-13, the model overestimates the impacts on births by about $12 \%$ (relative to Row A). Modeling temperature as a quadratic in monthly mean temperature (Row $G$ ) overstates the change in births by $14 \%$ since the quadratic model fails to capture an important tipping point at $70^{\circ} \mathrm{F}$ (see Figure 4 Panel B). One possible advantage of the quadratic model is that it allows for continuously greater impacts past $80^{\circ} \mathrm{F}$, unlike the binned model. Along those lines, the spline model projects a much larger 39\% decline in birth rates (Row $\mathrm{H}$ ) since the spline produces a larger response to extremely high temperatures (see Appendix Figure A7). As an 
aside, our estimates from the earlier sample period (1931-1969) suggest that climate change is likely to have a larger fertility impact on developing countries that "resemble" the pre-1970 United States. ${ }^{46}$

Part of the cost of climate change in terms of realized births will be offset by a change in birth seasonality. Given our estimates, we expect births to fall in the spring and early summer months relative to late summer and early winter. Figure 8 illustrates this fact using the estimates from the post-1970 model. We project the proportion of August births will increase by 4\% relative to April, which is large considering the baseline difference between 2000 and 2010 is $7 \%$. The model with only months 9 and 10 of exposure predicts a slightly smaller difference between August and April but higher birth rates in September through August. Importantly, the spline model predicts larger effects than the binned model. For example, the difference between August and April is $11 \%$ with the spline model. Thus, the measured inequality in economic status that is correlated with birth month could grow further under unabated climate change.

Similar to our back-of-the envelope calculation above, we project how this increased seasonality will affect infant health via exposure to hot days during the third trimester. For example, a shift in birth month from April to August would lead to an increased exposure risk of 36 more $>80^{\circ} \mathrm{F}$ days during the presumed third trimester (June, July, and August), which is in addition to the baseline current exposure of 25 days over these months. This calculation indicates climate-change-induced shift in birth months is projected to increase the risk of low birth weight by an additional 0.03 percentage points, or $0.4 \%$ increase relative to the average risk of $7.4 \%{ }^{47}$ Note that this increased risk of low birth weight would be in addition to the $5 \%$ increase in risk estimated by Deschenes et al. (2009) when holding birth seasonality constant. The shift in seasonality would be even greater in those developing countries that more closely resemble the pre-1970 United States.

\section{Conclusion}

In the United States, ambient temperature has a strong influence on birth rate dynamics. We find that unusually hot days cause a large fall in birth rates approximately 8 to 10 months later, followed by a partial rebound in birth rates at 11,12 , and 13 months. These dynamic estimates

\footnotetext{
46 For example, India has an estimated AC coverage of 2\% as 1999 (McNeil and Letschert, 2007) and a crude birth rate of approximately 20 per 1,000 (World Bank, 2013), both of which resemble the 1950s United States. ${ }^{47}$ We calculate (above) that temperature-induced birth seasonality caused a 0.05 percentage point increase in low birth weight in the 1970-2010 period.
} 
predict nearly half the seasonal variance in birth rates in the United States. Models that fail to account for the rebound in births can only account for one quarter of the seasonal variance. While our novel findings suggest that temperature is likely the single-most important determinant of birth seasonality in the United States, other environmental factors, like sunlight, may still have a large influence on birth seasonality and are worthwhile of exploration.

In terms of policy implications, our results indicate the costs of acute and unexpected environmental shocks are mitigated in the medium term by a shift in conception month. While this shift attenuates the impact on cumulative birth rates, it includes an important and overlooked health cost. The change in timing on its own may lead to worse infant health if parents are already timing births to maximize life course outcomes of the child. In the case of temperature, we find a shift in births from spring to late summer, when infant health outcomes are worse. While the causal link between season of birth and infant health remains an open research question, one causal channel could be increased exposure to high temperatures during the critical third trimester.

Our study also offers three important lessons for climate change. First, the projected increase in temperatures may reduce population growth rates in the United States. Using our estimates from the post-1970 period, we project a $2.6 \%$ decline in births in the United States, or about 107,000 births per year. Thus, climate change will exacerbate the already "belowreplacement" birth rates in the United States and similar developed countries, which may adversely affect the sustainability of social programs, like Social Security. Further, our historical estimates from the pre-1970 period suggest that climate change could have even larger impacts in developing countries.

Second, climate change is likely to increase the proportion of summer births and lead to worse infant health outcomes. For example, we find that August births will increase by $4 \%$ relative to April births using our core model. Our back-of-the envelope calculations suggest that these shifts may lead to a $0.4 \%$ increase in the relative risk of low birth weight. As with other early-life health shocks, recent evidence suggests there may be long-term consequences to this increased in utero exposure to high temperatures (Wilde et al., 2014; Isen et al., 2015). Taken together, these impacts suggest that fertility is an important and understudied cost of climate change in the United States and other countries.

Finally, we illustrate the scope for adapting to climate change using an existing technology. We document a large reduction in the temperature-fertility relationship over our 80year sample period and find that air conditioning can explain about one third of the dampening 
of this relationship over time. Echoing a recent study on mortality (Barreca et al., forthcoming), providing low-cost access to air conditioning may be an effective tool for mitigating the fertility costs of climate change throughout the world. However, the costs of increased air conditioning usage include increased greenhouse gas emissions, underscoring the fundamental dilemma in mitigating climate change impacts using energy-intensive technologies. 


\section{References}

Almond, Douglas, and Janet Currie. 2011. "Killing Me Softly: The Fetal Origins Hypothesis." Journal of Economic Perspectives, 25(3): 153-72.

Bailey, Martha J. 2006. "More Power to the Pill: The Impact of Contraceptive Freedom on Women's Lifecycle Labor Supply," Quarterly Journal of Economics 121 (1), February 2006: 289-320.

----. 2010. “Momma's Got the Pill: How Anthony Comstock and Griswold v. Connecticut Shaped U.S. Childbearing”, American Economic Review 100 (1), March 2010: 98-129.

Barreca, Alan 2012. "Climate Change, Humidity, and Mortality in the United States," Journal of Environmental Economics and Management, 63(1): 19-34.

Barreca, Alan, Karen Clay, Michael Greenstone, Olivier Deschenes, and Joseph Shapiro. Forthcoming. "Adapting to Climate Change: The Remarkable Decline in the U.S. Temperature-Mortality Relationship over the 20th Century." Journal of Political Economy.

Barreca, Alan, and Jay Shimshack. 2012. "Absolute Humidity, Temperature, and Influenza Mortality: 30 Years of County-Level Evidence from the United States." American Journal of Epidemiology, 176: S114-S122.

Becker, Gary S. and Nigel Tomes. 1976. "Child Endowments and the Quantity and Quality of Children." The Journal of Political Economy, 84(4) Part 2: S143-S162

Bronson, F.H., 2009. "Climate change and seasonal reproduction in mammals" Philosophical Transactions of the Royal Society, 364: 3331-3340.

Buckles, Kasey S. and Daniel M. Hungerman, 2013. "Season of Birth and Later Outcomes: Old Questions, New Answers" The Review of Economics and Statistics, 95(3): 711-724.

Burke, Marshall, John Dykema, David B. Lobell, Edward Miguel, and Shanker Satyanath. 2015. "Incorporating Climate Uncertainty into Estimates of Climate Change Impacts" The Review of Economics and Statistics, 97(2): 461-471.

Bureau of Economic Analysis. 2012. "Personal Income Summary." Accessed May 22, 2012 from: http://www.bea.gov/iTable/iTable.cfm?ReqID=70\&step=1\&isuri=1\&acrdn=4

Chen, Z., Toth, T., Godfrey-Bailey, L., Mercedat, N., Schiff, I. and Hauser, R. 2003. "Seasonal Variation and Age-Related Changes in Human Semen Parameters." Journal of Andrology, 24: $226-231$.

Connolly, Marie. 2008. "Here comes the rain again: Weather and the intertemporal substitution of leisure." Journal of Labor Economics 26(1): 73-100.

Currie, Janet, and Hannes Schwandt. 2013. "Within-mother analysis of seasonal patterns in health at birth." PNAS, 110(30): 12265-12270.

Dada, R., Gupta, N.P., and Kucheria, K. 2001. "Deterioration Of Sperm Morphology In Men Exposed To High Temperature." Journal Of The Anatomical Society of India, 50(2): 107111.

Dadvand, Payam, Xavier Basagana, Claudio Sartini, Francesc Figueras, Martine Vrijheid, Audrey de Nazelle, Jordi Sunyer, and Mark J. Niuwenhuijsen, 2011. "Climate Extrememes and the Length of Gestation”, Environmental Health Perspectives, 119(10):1449-1453.

Darwin, Charles. 1859. On the Origin of Species. London: John Murray.

Dell, Melissa, Benjamin F. Jones, and Benjamin A. Olken. 2014. "What Do We Learn from the Weather? The New Climate-Economy Literature." Journal of Economic Literature, 52(3): 740-798.

Deng, Boer. 2014. "A Time to Be Born: Why do birth rates peak at different times in different places?" Slate April 28, 2014.

Deryugina, Tatyana and Solomon M. Hsiang. 2014. "Does the Environment Still Matter? Daily Temperature and Income in the United States." NBER working paper No. 20750. 
Deschenes, Olivier, Michael Greenstone, and Jonathan Guryan, 2009. "Climate Change and Birth Weight”. American Economic Review: Papers and Proceedings, 99(2): 211-217.

Deschenes, Olivier. 2012. "Climate Change, Human Health, and Adaptation: A Review of the Empirical Literature" NBER Working Paper No. 18345

Deschenes, Olivier, and Michael Greenstone. 2011. "Climate Change, Mortality, and Adaptation: Evidence from Annual Fluctuations in Weather in the U.S." American Economic Journal: Applied Economics, 3(4): 152-185

Deschenes, Olivier, and Enrico Moretti. 2009. "Extreme Weather Events, Mortality and Migration." Review of Economics and Statistics 91(4): 659-681.

Dimitri, Carolyn, Anne Effland, and Neilson Conklin. 2005. "The 20th Century Transformation of U.S. Agriculture and Farm Policy." United States Department of Agriculture (USDA) Economic Information Bulletin Number 3, June 2005.

Ellison, Peter T., Claudia R. Valeggia and Diana S. Sherry. 2005. "Human birth seasonality" in Seasonality in Primates: Studies of Living and Extinct Human and Non-Human Primates, ed. Diane K. Brockman and Carel P. van Schaik. Published by Cambridge University Press.

Evans, J.J. and G.M. Anderson. 2012. "Balancing ovulation and anovulation: integration of the reproductive and energy balance axes by neuropeptides" Human Reproduction Update, 18(3): 313-332.

Fehring, Richard J., Mary Schneider, and Kathleen Raviele. 2006. "Variability in the Phases of the Menstrual Cycle." Journal of Obstetric, Gynecologic, \& Neonatal Nursing, 35(3): 376 384.

Goldin, C. 2006. "The Quiet Revolution that Transformed Women's Employment, Education, and Family" NBER Working Paper No. 11953.

Goldin, C. and L.F. Katz. 2002. "The power of the pill: Oral contraceptives and women's career and marriage decisions". Journal of Political Economy 110(4): 730-770.

Guldi, M. 2008. "Fertility Effects of Abortion and Pill Access for Minors" Demography, 45(4): 817-827.

Goss, Stephen C. 2010. “The Future Financial Status of the Social Security Program” Social Security Bulletin, Vol. 70, No. 3.

Graff Zivin, Joshua and Matthew Neidell. 2014. "Temperature and the Allocation of Time: Implications for Climate Change," Journal of Labor Economics, 32(1): 1-26.

Haines, Michael R., and the Inter-university Consortium for Political and Social Research. 2004. "Historical, Demographic, Economic, and Social Data: The United States, 1790-2000." Inter-University Consortium for Political and Social Research, Ann Arbor, MI: Interuniversity Consortium for Political and Social Research.

Hansen, Peter J. 2009. "Effects of Heat Stress on Mammalian Reproduction", Philosophical Transactions of the Royal Society B: Biological Sciences, 364:3341-3350; DOI: 10.1098/rstb.2009.0131.Published 15 October 2009.

Hornbeck, Richard. 2012. "The Enduring Impact of the American Dust Bowl: Short- and LongRun Adjustments to Environmental Catastrophe." American Economic Review, 102(4): $1477-1507$

Hoynes, Hilary W. and Diane Whitmore Schanzenback. 2009. "Consumption Responses to InKind Transfers: Evidence from the Introduction of the Food Stamp Program." American Economic Journal: Applied Economics 1(4): 109-139

International Panel on Climate Change (IPCC). 2014. Climate Change 2014: Synthesis Report. Contribution of Working Groups I, II and III to the Fifth Assessment Report of the Intergovernmental Panel on Climate Change [Core Writing Team, R.K. Pachauri and L.A. Meyer (eds.)]. IPCC, Geneva, Switzerland, 151 pp. 
Isen, Adam, Maya Rossin-Slater, and W. Reed Walker. 2015. “Heat and Long-Run Human Capital Formation." Unpublished working paper.

Lam, David and Jeffrey Miron. 1991a. "Seasonality of Births in Human Populations". Social Biology, 38(1-2): 51-78.

----. 1991b. "Temperature and the Seasonality of Births," in Adrian Zorgniotti, editor, Temperature and Environmental Effects on the Testis, Advances in Experimental and Environmental Biology: V. 286, Plenum Press, pp. 73-88.

----. 1994. "Global Patterns of Birth Seasonality in Human Populations," in Kenneth L. Campbell and James W. Wood, editors, Human Reproductive Ecology: Interactions of Environment, Fertility, and Behavior, Annals of the New York Academy of Sciences, vol. 709, pp. 9-28.

---. 1996. "The Effects of Temperature on Human Fertility", Demography 33(3): 291-305.

Lam, David A., Jeffrey A. Miron, and Ann Riley. 1994. "Modeling Seasonality in Fecundability, Conceptions, and Births". Demography, 31(2): 321-346.

Levin, M. L., Xu, X. and Bartkowski, J. P., 2002. Seasonality of Sexual Debut. Journal of Marriage and Family, 64: 871-884.

Levine , Phillip B., Douglas Staiger, Thomas J. Kane, David J. Zimmerman. 1996. “Roe v. Wade and American Fertility" NBER Working Paper No. 5615.

Levine, Richard J. 1991. "Seasonal Variation in Human Semen Quality" in Adrian Zorgniotti, editor, Temperature and Environmental Effects on the Testis, Advances in Experimental and Environmental Biology: V. 286, Plenum Press, pp 89-96.

Lowen, A.C. and Steel, J., 2014. "Roles of Humidity and Temperature in Shaping Influenza Seasonality", Journal of Virology. 88(14): 7692-7695.

McNeil, Michael A. and Virginie E. Letschert. 2007. "Future air conditioning energy consumption in developing countries and what can be done about it: the potential of efficiency in the residential sector." In European Council for an Energy Efficient Economy 2007 Summer Study.

Meade, Melinda S. and Robert J. Earickson. 2000. "Medical geography.” New York: Guilford Press.

Menne, M.J., I. Durre, B. Korzeniewski, S. McNeal, K. Thomas, X. Yin, S. Anthony, R. Ray, R.S. Vose, B.E.Gleason, and T.G. Houston. 2012. “Global Historical Climatology Network Daily (GHCN-Daily)". Version 3.12. NOAA National Climatic Data Center. http://doi.org/10.7289/V5D21VHZ. Accessed October 14, 2014.

Miguel, Edward, and Gerard Roland. 2011. "The long-run impact of bombing Vietnam." Journal of Development Economics, 96: 1-15

National Cancer Institute. 2013. U.S. Population Estimates 1968-2005. Downloaded from /http://seer.cancer.gov/popdata/download.htmIS.

National Climatic Data Center. 2013. Global Summary of the Day Files: 1930-2011. Downloaded from /ftp://ftp.ncdc.noaa.gov/pub/data/gsod/S.

National Center for Health Statistics (1978-1989). Natality Birth Files. National Center for Health Statistics, Hyattsville, Maryland.

National Vital Statistics of the United States, 1931-1967 reports, http://www.cdc.gov/nchs/products/vsus.htm, accessed on 5-9-13.

Rodgers, J.L., D.F. Harris, and K.B. Vickers. 1992. "Seasonality of First Coitus in the U.S." Social Biology, 39(1-2): 1-14.

Rodgers, J.L. and J.R. Udry. 1988. "The Season-of-Birth Paradox." Social Biology, 35(3-4): 17185.

Ruggles, Steven, J. Trent Alexander, Katie Genadek, Ronald Goeken, Matthew B. Schroeder, and Matthew Sobek. 2010. Integrated Public Use Microdata Series: Version 5.0. Minneapolis: University of Minnesota. 
Sanders, Nicholas J. and Charles F. Stoecker. 2011. "Where Have All the Young Men Gone? Using Gender Ratios to Measure Fetal Death Rates." NBER Working Paper No. 17434.

Seiver, Daniel A., 1985. "Trend and Variation in the Seasonality of U.S. Fertility, 1947-1976", Demography, 22(1): 89-100.

Seiver, Daniel A., 1989. "Seasonality of Fertility: New Evidence”, Population and Environment, 10(4): 245-257.

Shaman J, and Kohn M. 2009. "Absolute humidity modulates influenza survival, transmission, and seasonality". Proc. Natl. Acad. Sci. U. S. A. 106: 3243-3248.

Smith, V. Kerry, Jared C. Carbone, Jaren C. Pope, Daniel G. Hallstrom, Michael E. Darden. 2006. "Adjusting to natural disasters." Journal of Risk and Uncertainty, September 2006, Volume 33(1): 37-54.

Strand, Linn B., Barnett, Adrian R., Tong, Shilu. 2011. "The influence of season and ambient temperature on birthoutcomes: A review of the epidemiological literature" Environmental Research, 111(3): 319-472.

Svartberg, J., Jorde, R., Sundsfjord, J., Bønaa, K.H., and Barrett-Connor E. 2003. "Seasonal variation of testosterone and waist to hip ratio in men: the Tromsø study" Journal of Clinical Endocrinology and Metabolism, 88(7):3099-104.

Trivers, Robert L. and Dan E. Willard. 1973. "Natural Selection of Parental Ability to Vary the Sex Ratio of Offspring." Science, 179 (4068): 90.

Udry, J. Richard, and Naomi M. Morris. 1967. "Seasonality of Coitus and Seasonality of Birth", Demography, 4 (2): 673-679.

United Nations Statistics Division. 2014. "Live births by month of birth." Downloaded on August 7, 2014 from \url\{http://data.un.org/Data.aspx?d=POP\&f=tableCode:55\}

Wernerfelt, Nils, David Slusky, and Richard Zeckhauser. 2014. "Second Trimester Sunlight and Asthma: Evidence from Two Independent Studies." NBER working paper.

Wilcox, Allen J., Clarice R. Weinberg, Donna D. Baird. 1995. "Timing of Sexual Intercourse in Relation to Ovulation." New England Journal of Medicine 333(23): 1517-1521.

Wilde, Joshua, Benedicte Apouey, and Toni Jung. 2014. "Heat Waves at Conception and Later Life Outcomes." University of Southern Florida working paper.

World Bank. 2013. Fertility statistics. Downloaded from http://data.worldbank.org/indicator/SP.DYN.TFRT.IN July 7, 2013. 
Figure 1: Seasonality in Average Daily Births: United States, Germany, and Australia, 2000-2010

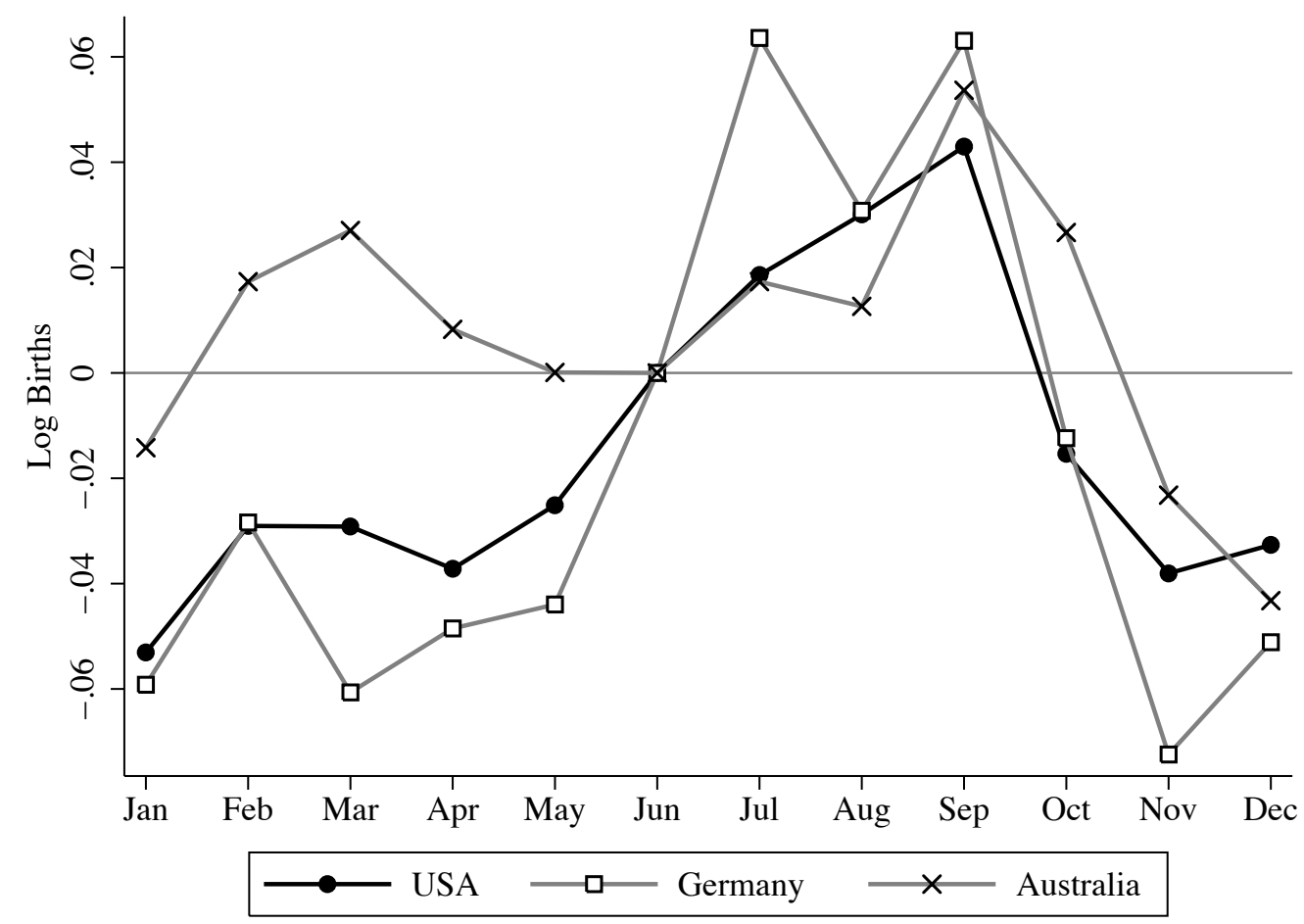

Note: The $y$-axis is the difference in log points between the average number of daily births in a given month relative to June. These data come from the United Nations Statistics Division (2014). 
Figure 2: Daily Birth Rate per 100,000 Residents, 1931-2010

Panel A: Differences by census region

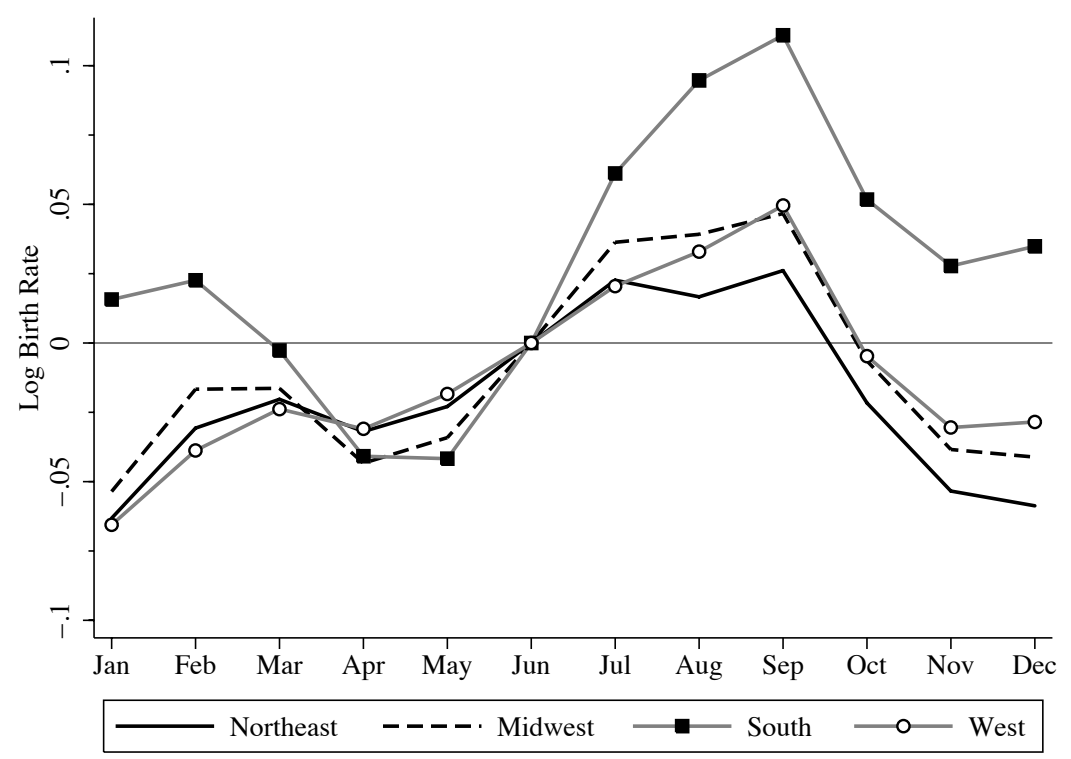

Panel B: Differences by time period

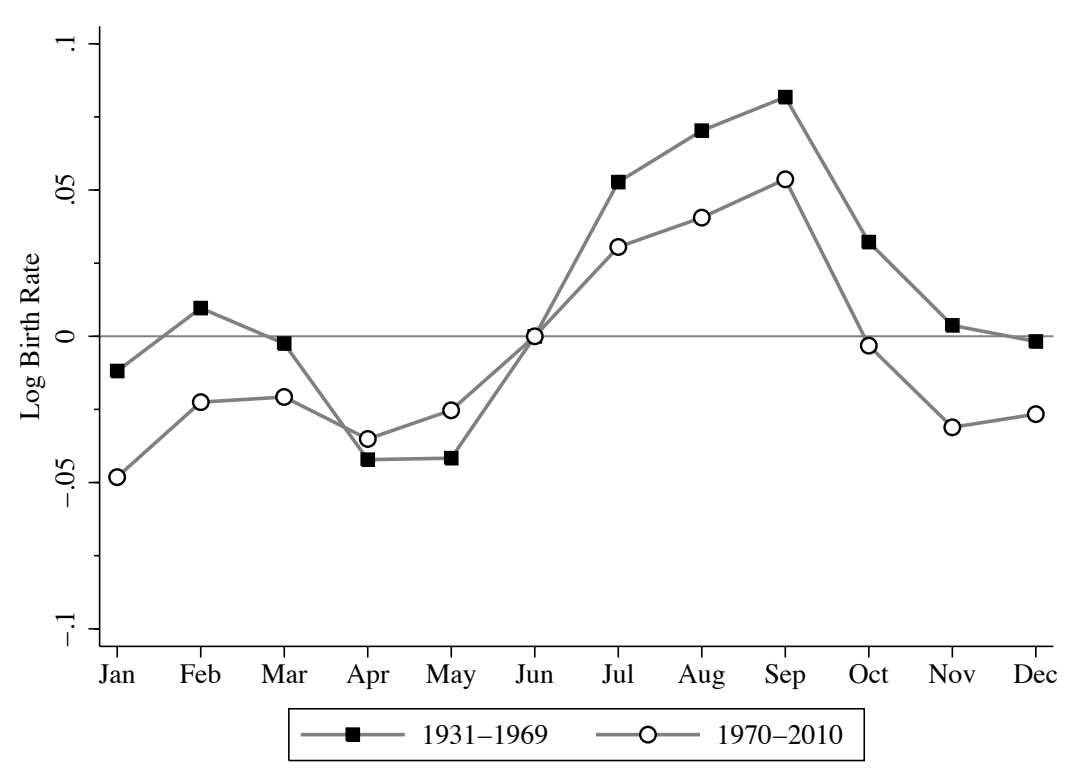

Note: Calculations use state-year populations as weights. 
Figure 3: Estimated Temperature-Fertility Relationship: Effect of Daily Mean Temperature $>80{ }^{\circ} \mathrm{F}$ Relative to $60-70$ ${ }^{\circ} \mathrm{F}$ on Log Birth Rate, by Months from Exposure

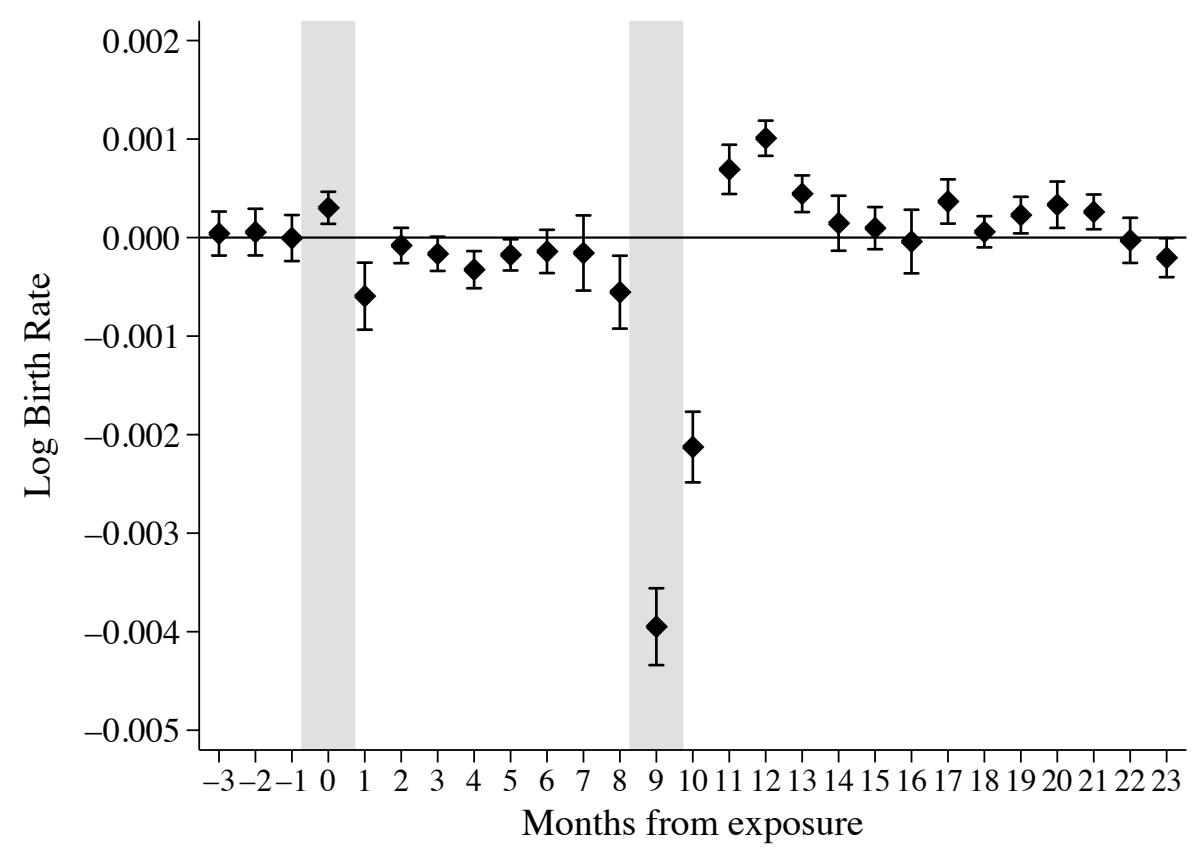

Note: The diamonds are the point estimates and the brackets represent $+/-$ two standard errors. The estimates can be interpreted as the impact on the log monthly birth rate, in log points, of one additional day with a mean temperature $>80{ }^{\circ} \mathrm{F}$ relative to $60-70{ }^{\circ} \mathrm{F}$. The model has year-month fixed effects, state-by-calendar-month fixed effects, state-by-calendar month quadratic time trends, and state-year fixed effects. We control for fraction of days with precipitation between 0.01 and 0.50 inches and over 0.51 inches in each month. In addition, we control for effects for up to 24 months after exposure (and 3 months prior to exposure as a placebo check). Estimates are weighted by state-year population. Standard errors are clustered at the state-level. The gray shading highlights both 0 and 9 months from exposure. 
Figure 4: Estimated Temperature-Fertility Relationship: Effect of Daily Mean Temperatures on Log Birth Rate 9 Months Later

Panel A: Core estimates with standard errors

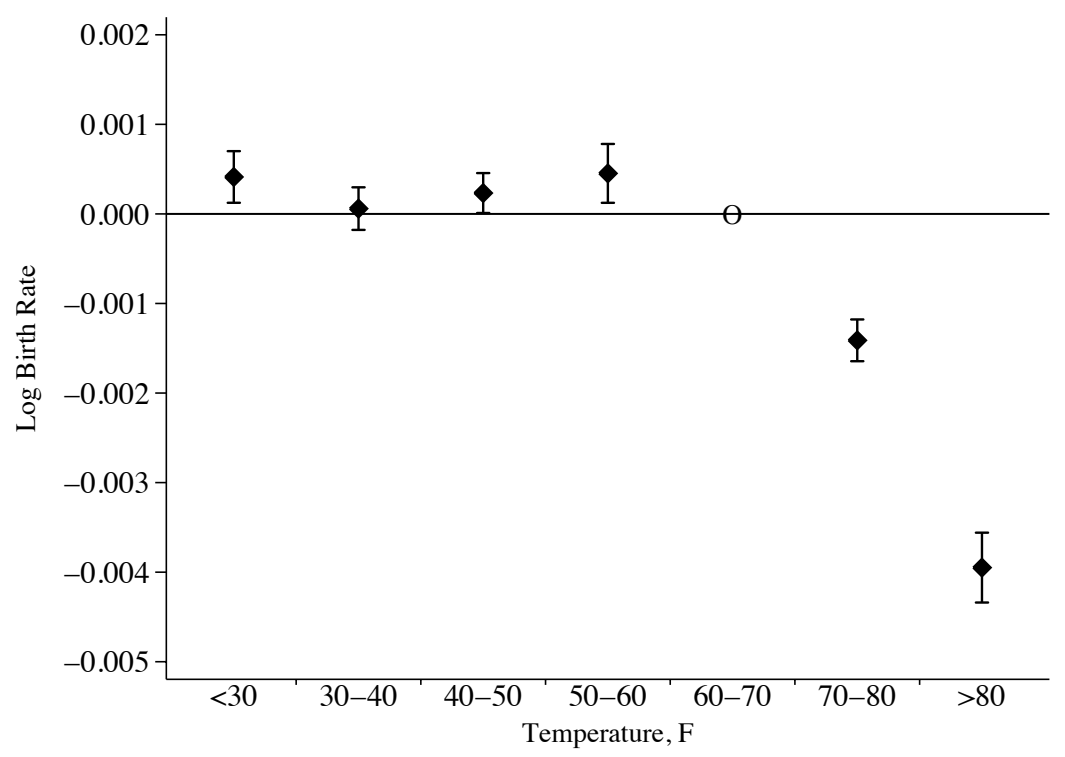

Panel B: Comparison with monthly quadratic model

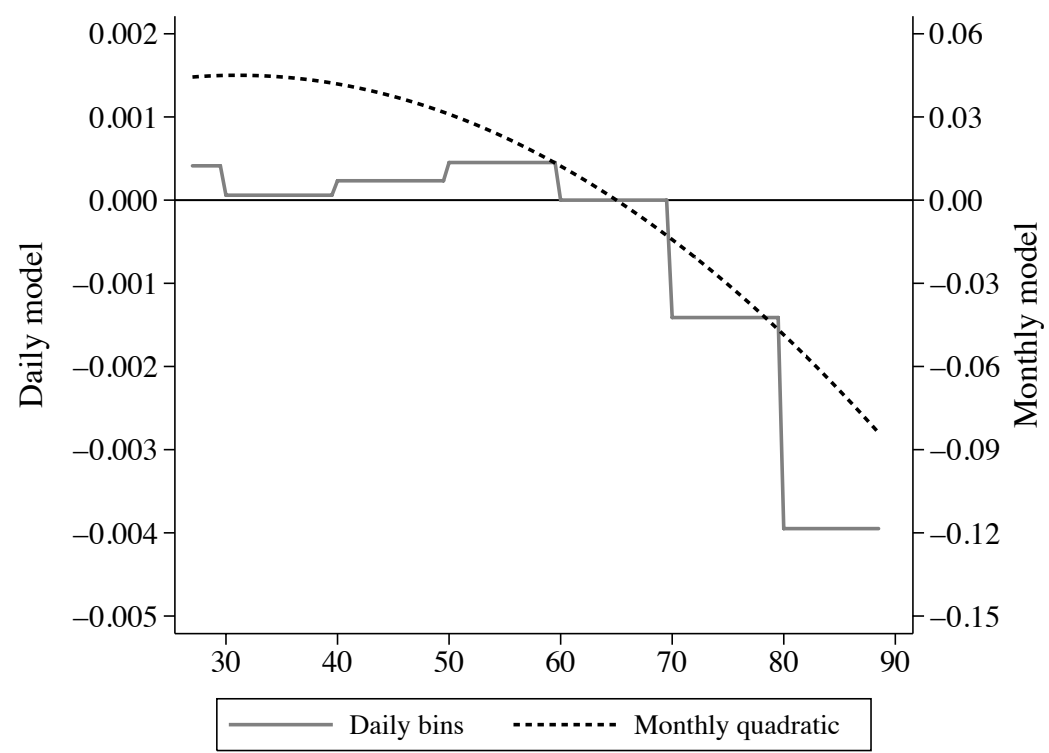

Note: In Panel A, the diamonds are the point estimates and the brackets represent two standard errors around the point estimates. In Panel B, the "daily bins" model refers to our core model. See note to Figure 3 for details on that model. The "monthly quadratic" model has identical controls to our core model except temperature is a quadratic function of the monthly mean temperature. 
Figure 5: Model Predictions of Log Birth Rate

Panel A: Predictions vs. actual, United States

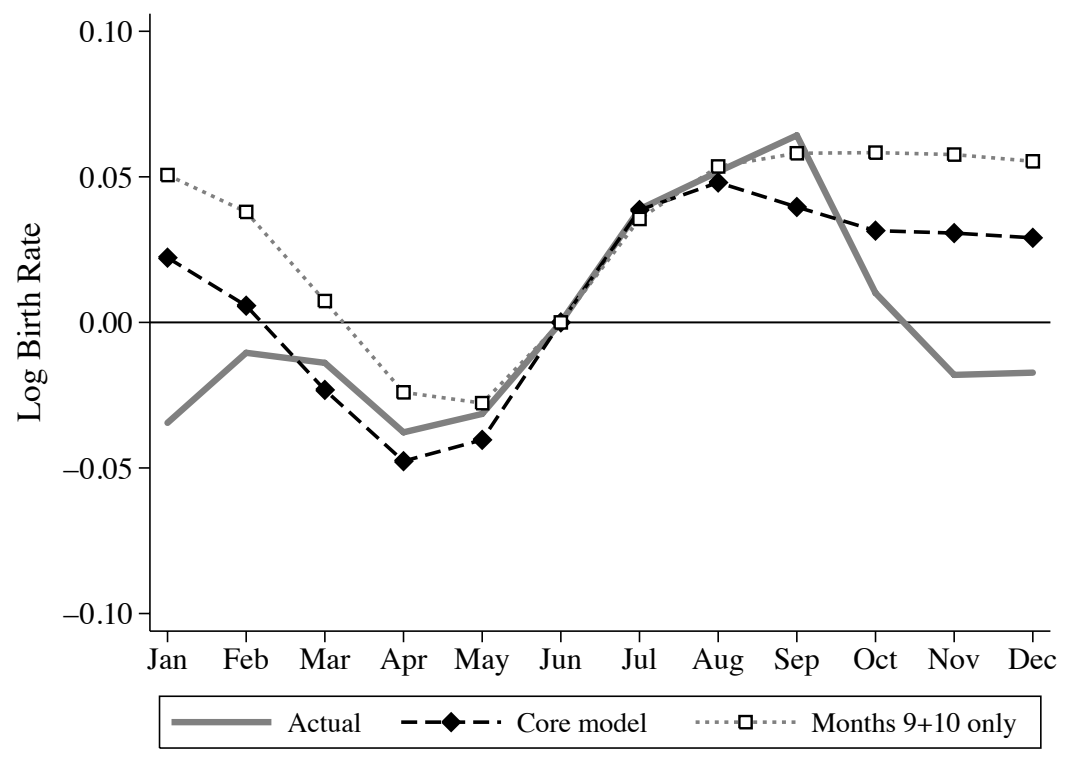

Panel B: Predictions, by census region

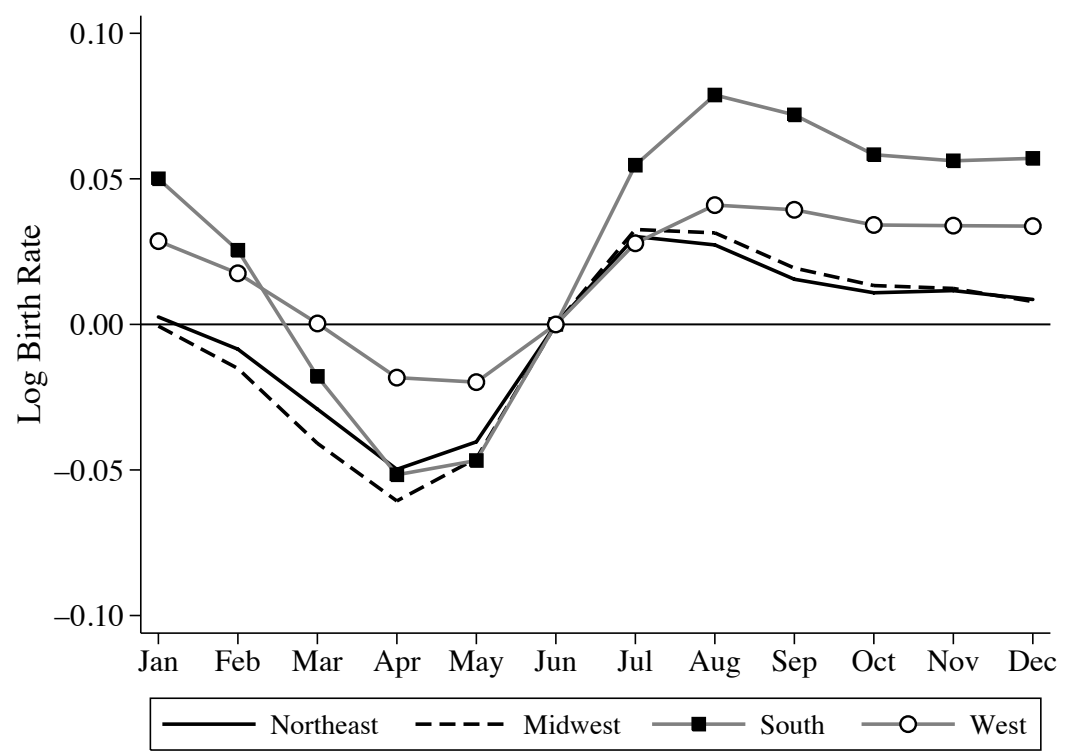

Note: See note to Figure 3 for details on the core model, which controls for the full set of exposure months $(-3,-2$, $\ldots,+23)$. In Panel A, the "Months $9+10$ only" model only controls for exposure in months 9 and 10 . We use only the temperature estimates to make these predictions, and ignore rainfall and all other controls. We recenter both the observed and predicted values around June so the values should be interpreted as deviations, in log points, from June. 
Figure 6: Estimated Temperature-Fertility Relationship: Effect of Daily Mean Temperature $>80^{\circ} \mathrm{F}$ Relative to $60-70$ ${ }^{\circ} \mathrm{F}$ on Log Birth Rate 9 Months Later, by Decade

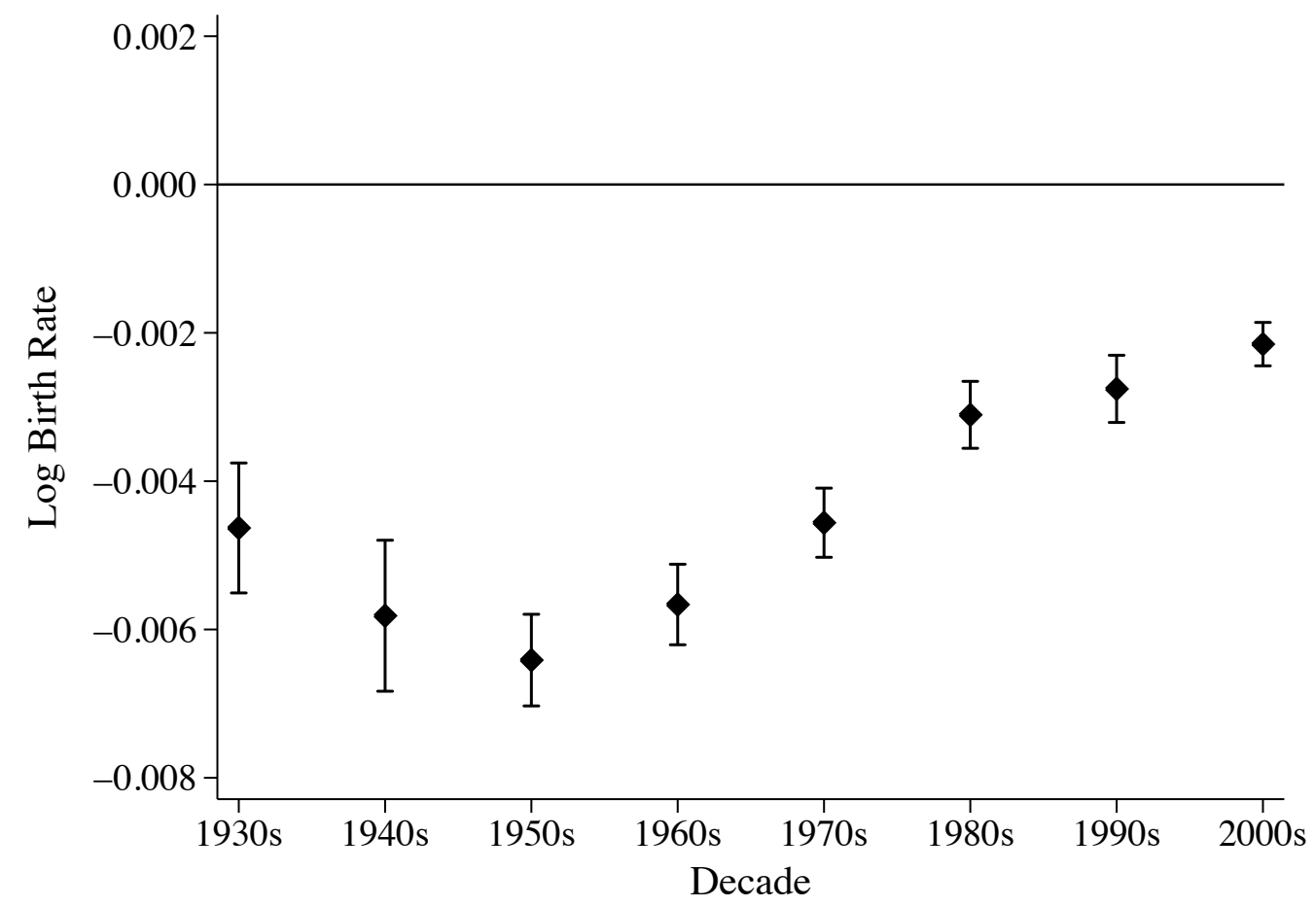

Note: The diamonds are the point estimates and the brackets represent $+/-$ two standard errors. We restrict the exposure months $0-13$. We use the full sample of years and interact the temperature variables with an indicator for the given decade. We include 2010 in the 2000s. See note to Figure 3 for details on the other model controls. 
Figure 7: Impact of Residential Air Conditioning on the Fertility-Temperature Relationship: Effect of Daily Mean Temperatures on Log Birth Rate 9 Months Later

Panel A: Main effect of temperature

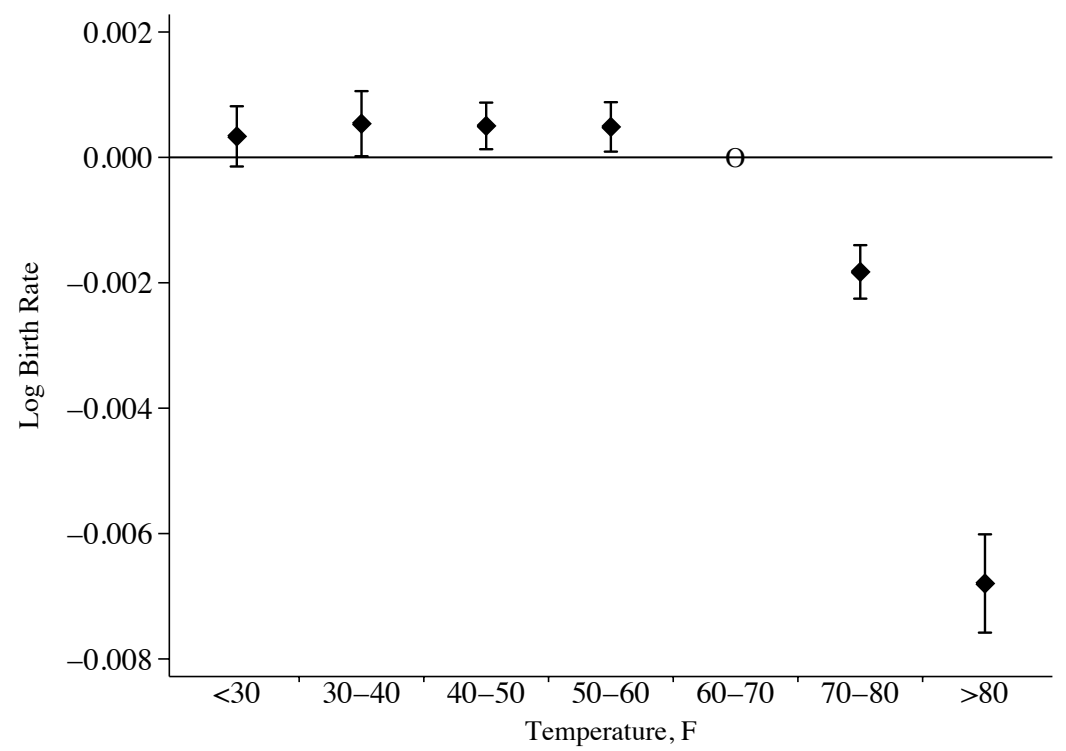

Panel B: Temperature-AC interaction

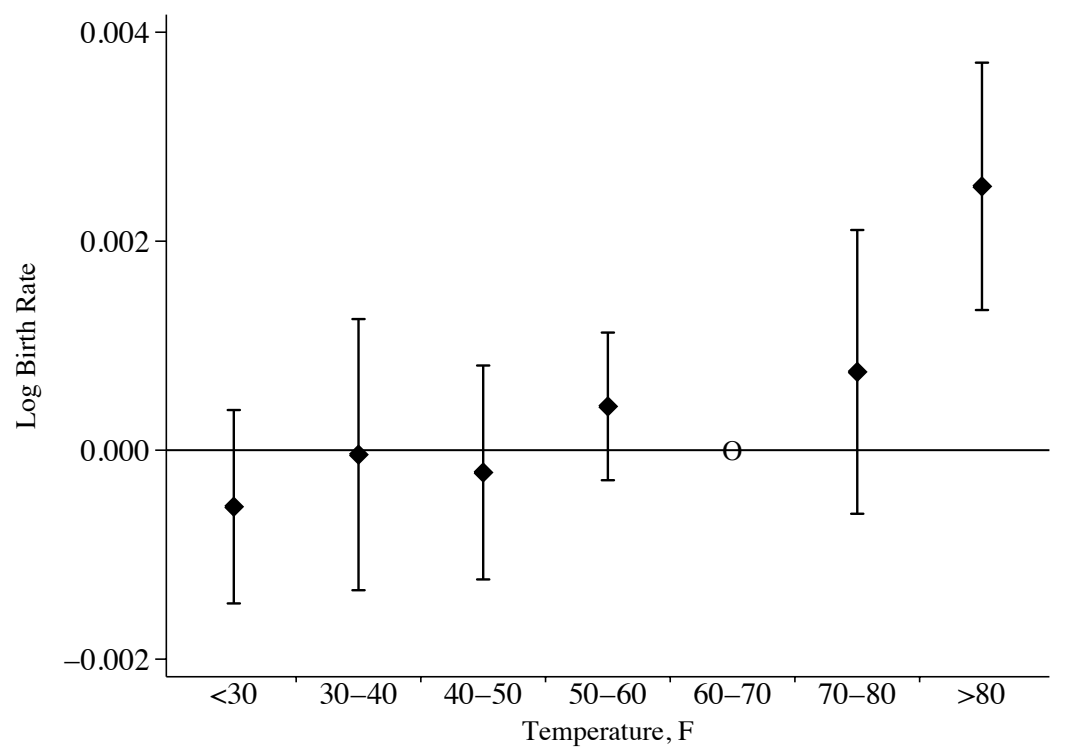

Note: Y-axes scales vary across panels. These are the estimates from equation with temperature variables as a main effect and the temperature variables interacted with the $A C$ variable. We also control for time (linear) interacted with the temperature variables. The model has similar controls as above. We allow for effects across months 0 through 13 . Estimates are weighted by state-year population. Standard errors are clustered at the state level. The sample period is 1960 through 2010. 
Figure 8: Projected Changes in Birth Seasonality by 2070-2099, According to Error-Corrected Hadley CM3 A1FI

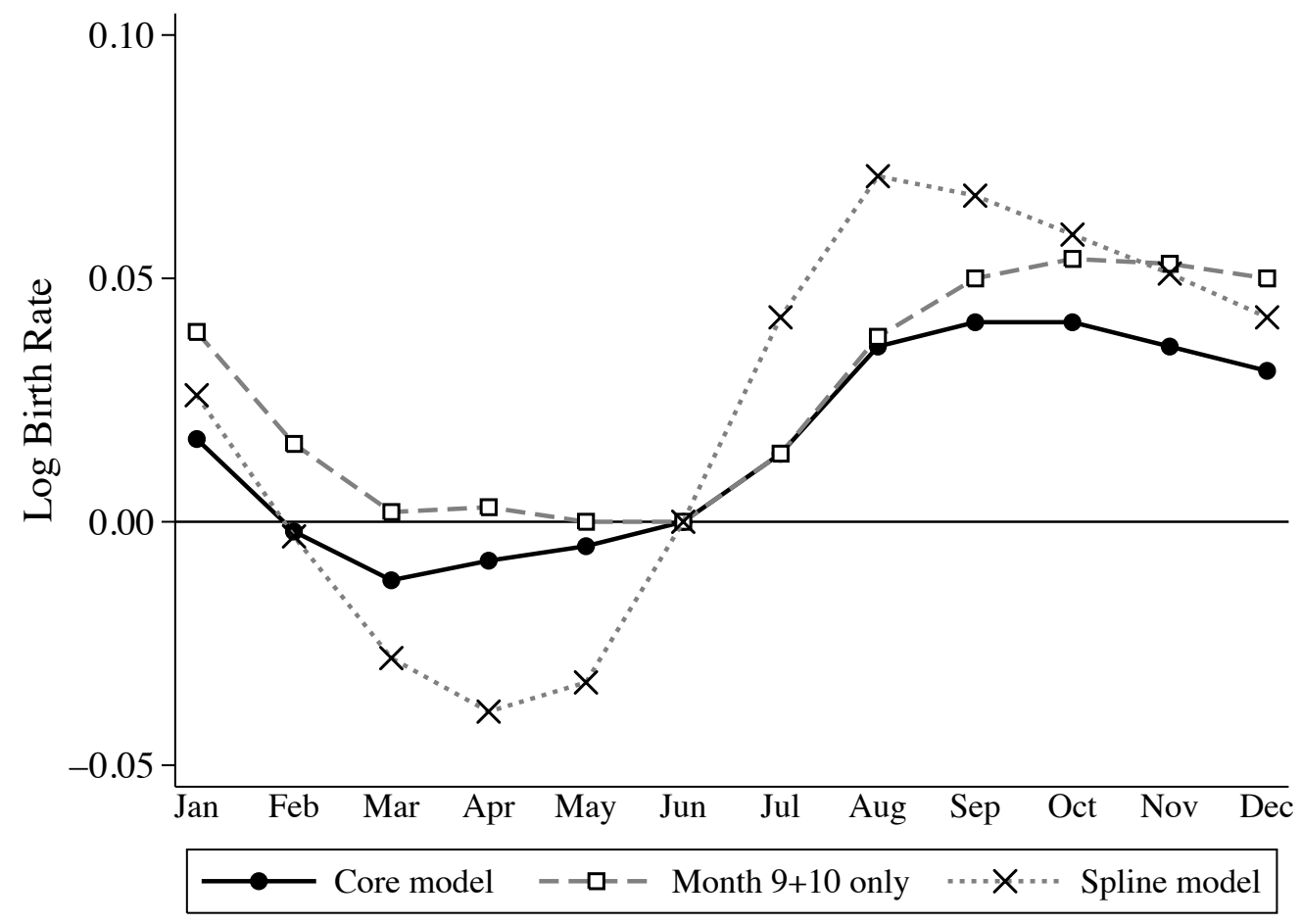

Note: Average exposures estimated using county population estimates in 2000 as weights. The climate change projections are "error corrected" to factor out the difference between the realized temperatures and model predictions for the 1990-2002 time period. The "Core model" projects changes in birth rates using the post-1970 temperature estimates from Table 3 Panel B. The "Months $9+10$ only" model only controls for exposure in months 9 and 10 . The "Spline model" controls for temperature as a cubic polynomial spline with knots at $10,30,50,70$, and $90{ }^{\circ} \mathrm{F}$ across the same exposure months as the "Core model". 


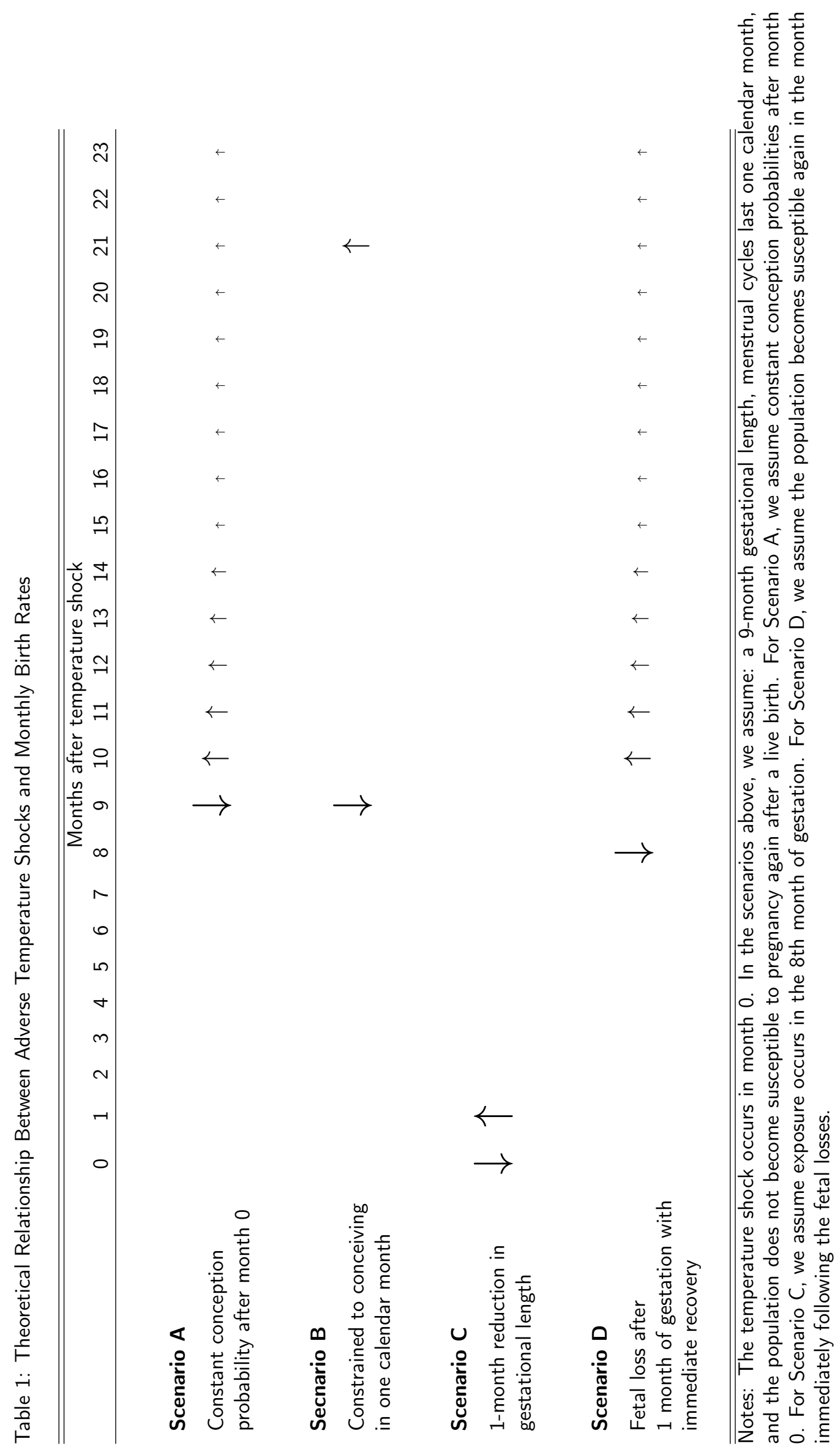


Table 2: Summary Statistics on Daily Birth Rates and Daily Weather, 1931-2010

\begin{tabular}{|c|c|c|c|c|c|}
\hline Sample: & All states & Northeast & Midwest & South & West \\
\hline Daily births per 100,000 residents & 4.7 & 4.3 & 4.7 & 4.9 & 4.9 \\
\hline Mean temp $(F)<30$ & 2.9 & 4.2 & 5.3 & 0.8 & 1.3 \\
\hline Mean temp (F) 30-40 & 3.4 & 4.9 & 4.6 & 2.2 & 2.1 \\
\hline Mean temp (F) 40-50 & 4.4 & 5.1 & 4.3 & 3.9 & 4.5 \\
\hline Mean temp (F) 50-60 & 5.6 & 5.2 & 4.7 & 5.1 & 8.5 \\
\hline Mean temp (F) 60-70 & 6.1 & 5.7 & 5.5 & 5.9 & 8.2 \\
\hline Mean temp (F) 70-80 & 5.8 & 4.7 & 5.1 & 7.9 & 4.2 \\
\hline Mean temp $(F)>80$ & 2.3 & 0.6 & 1.0 & 4.7 & 1.5 \\
\hline No precipitation & 21.4 & 19.7 & 20.8 & 21.6 & 24.3 \\
\hline Precipitation $=0.00-0.50$ inches & 7.0 & 8.3 & 7.8 & 6.4 & 5.1 \\
\hline Precipitation $=0.50+$ inches & 2.1 & 2.4 & 1.9 & 2.5 & 1.0 \\
\hline Number of state-months & 47,004 & 8,640 & 11,508 & 16,296 & 10,560 \\
\hline Number of states & 49 & 9 & 12 & 17 & 11 \\
\hline
\end{tabular}

Notes: For temperature and precipitation, the data represent average number of days per month. Calculations use state-year populations as weights. The births are by state of residence for the years 1942 on, while state of occurrence is only available in the 1931-1941 period. South Dakota does not enter the sample until 1932 and Texas does not enter until 1933. Alaska and Hawaii are excluded from the sample. Washington DC is treated as a state in our analyses. 


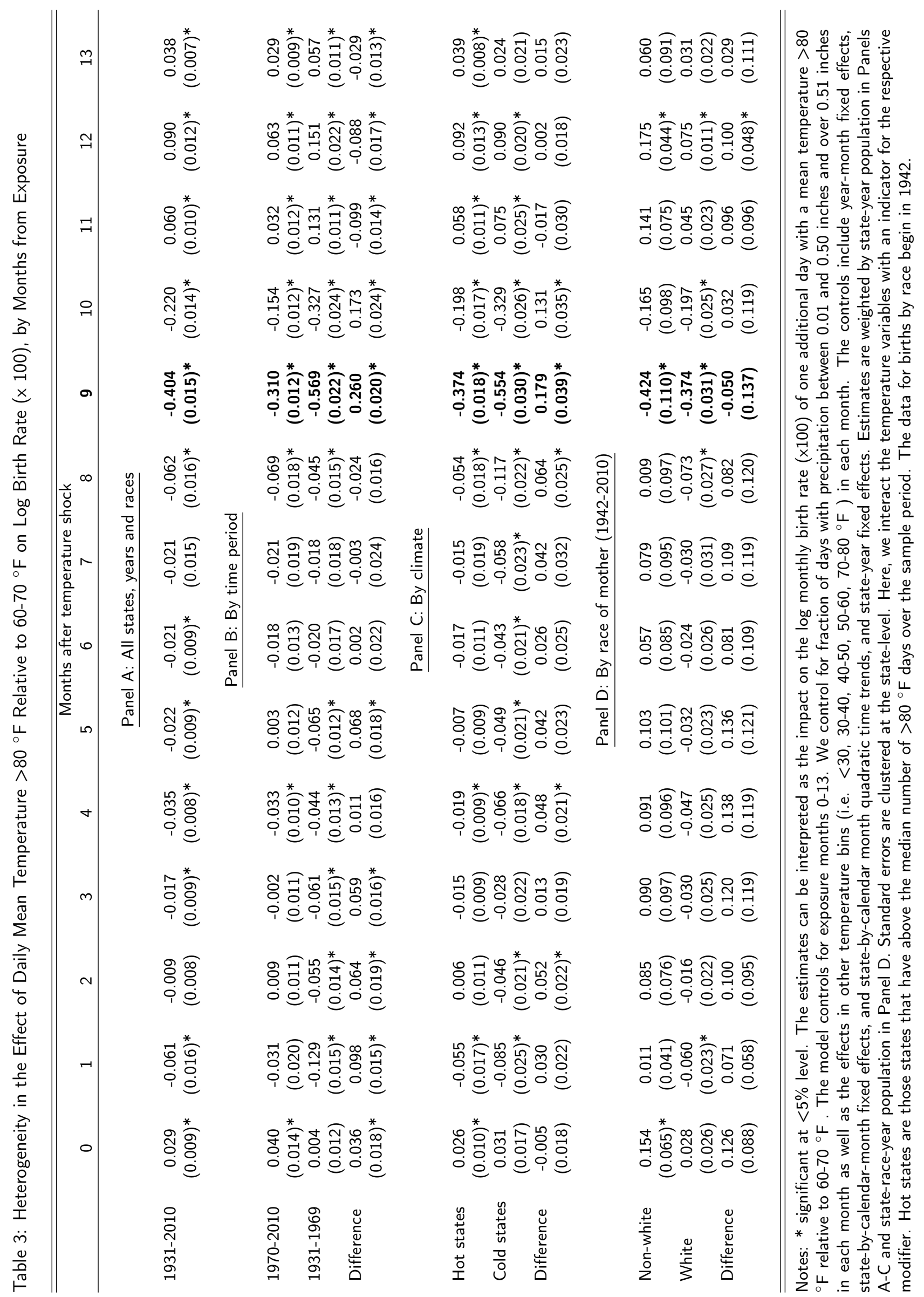




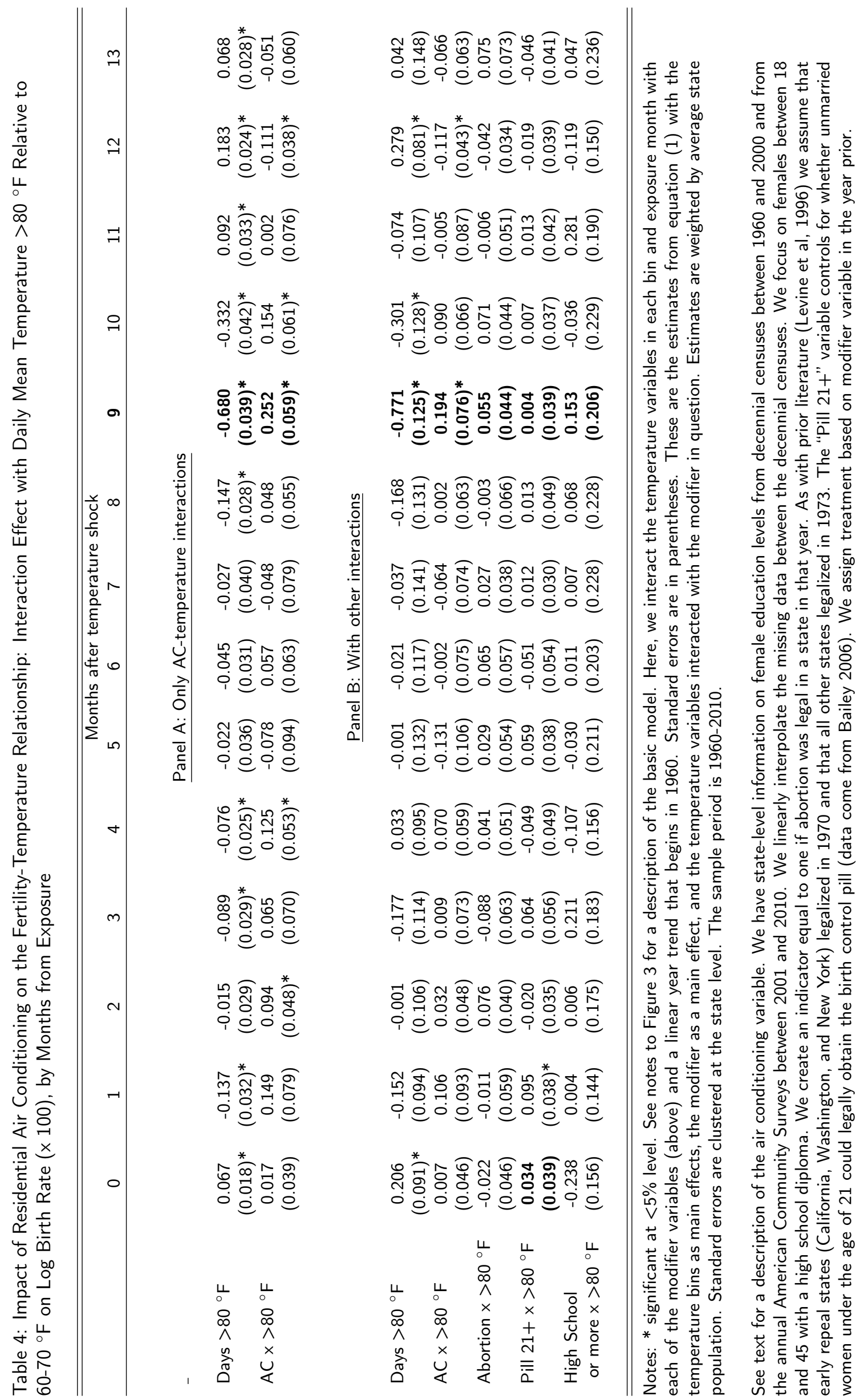


Table 5: Projected Change in Log Birth Rate and Total Births by 2070-2099, Based on Error-Corrected Hadley CM3 $\mathrm{A} 1 \mathrm{FI}$

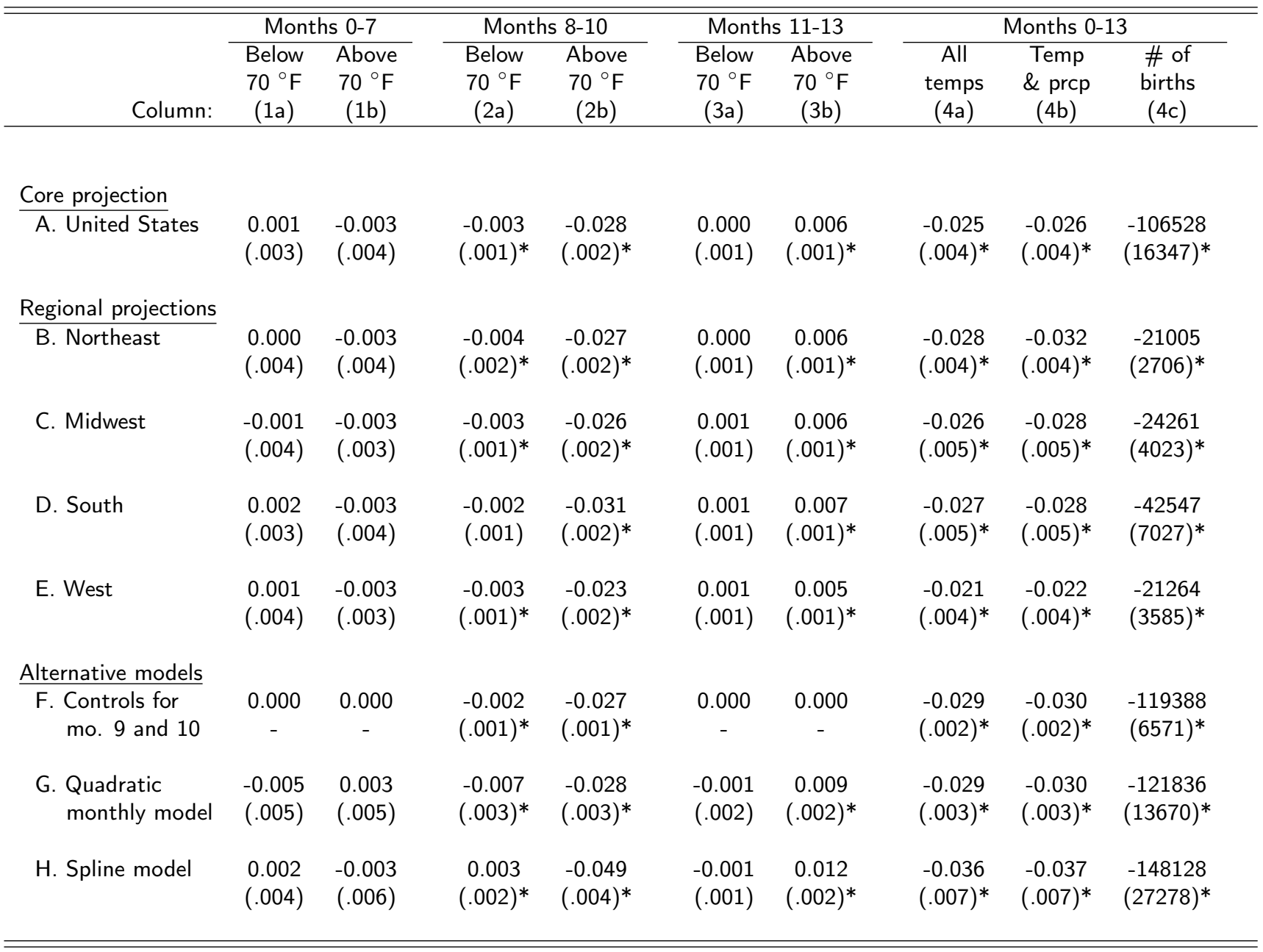

Notes: * significant at $<5 \%$ level. All projections are relative to the climatic averages between 1990 and 2002 , but are "error corrected" to factor out the difference between the realized temperatures and model predictions for the 1990-2002 time period. The projected change in birth rates in rows A through E use our post- 1970 temperature estimates from Table 3 Panel B. The Panel $\mathrm{F}$ only controls for exposure in months 9 and 10. Panel $\mathrm{G}$ controls for temperature as a quadratic in monthly mean temperature across the same exposure months as the "Core model". Panel H controls for temperature as a cubic polynomial spline with knots at $10,30,50,70$, and $90^{\circ} \mathrm{F}$ across the same exposure months as the "Core model". The change in births is calculated using the average number of births between 2000 and 2010 . The sample is restricted to the continental United States. 
Appendix Section A: Robustness Checks and Supporting Exhibits 
Figure A1: Annual Means of Log Birth Rates and Days $>80^{\circ} \mathrm{F}$, by Census Region

Panel A: Log birth rates

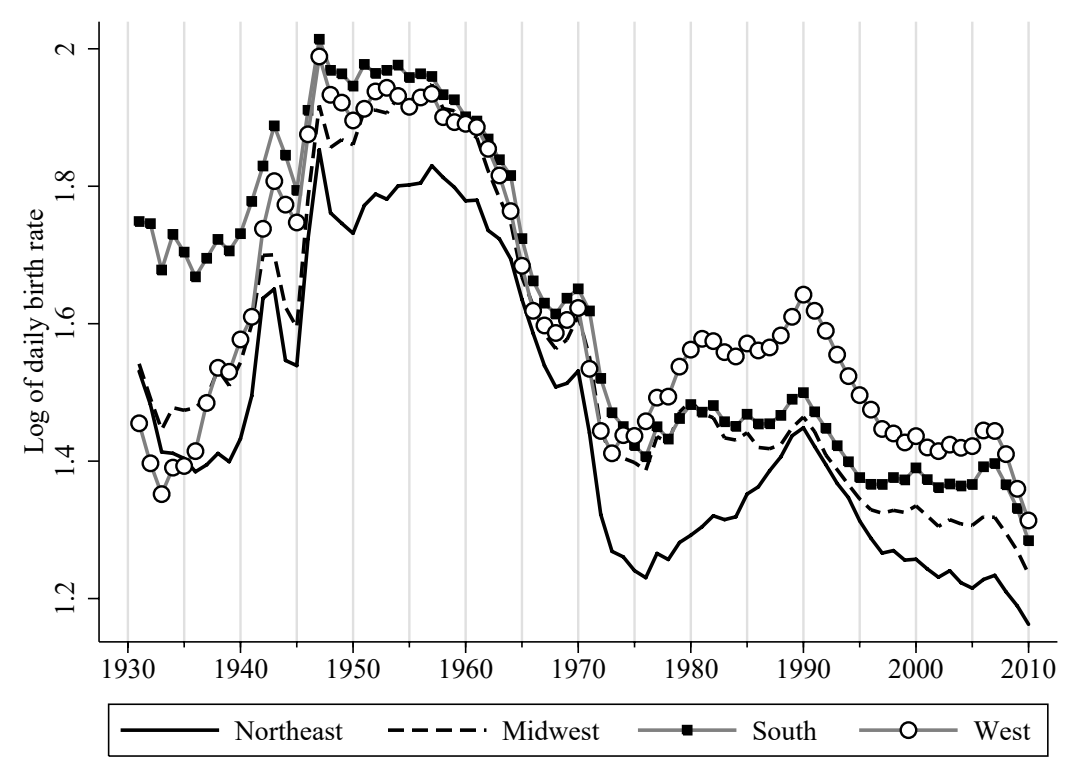

Panel B: Days $>80^{\circ} \mathrm{F}$ per month

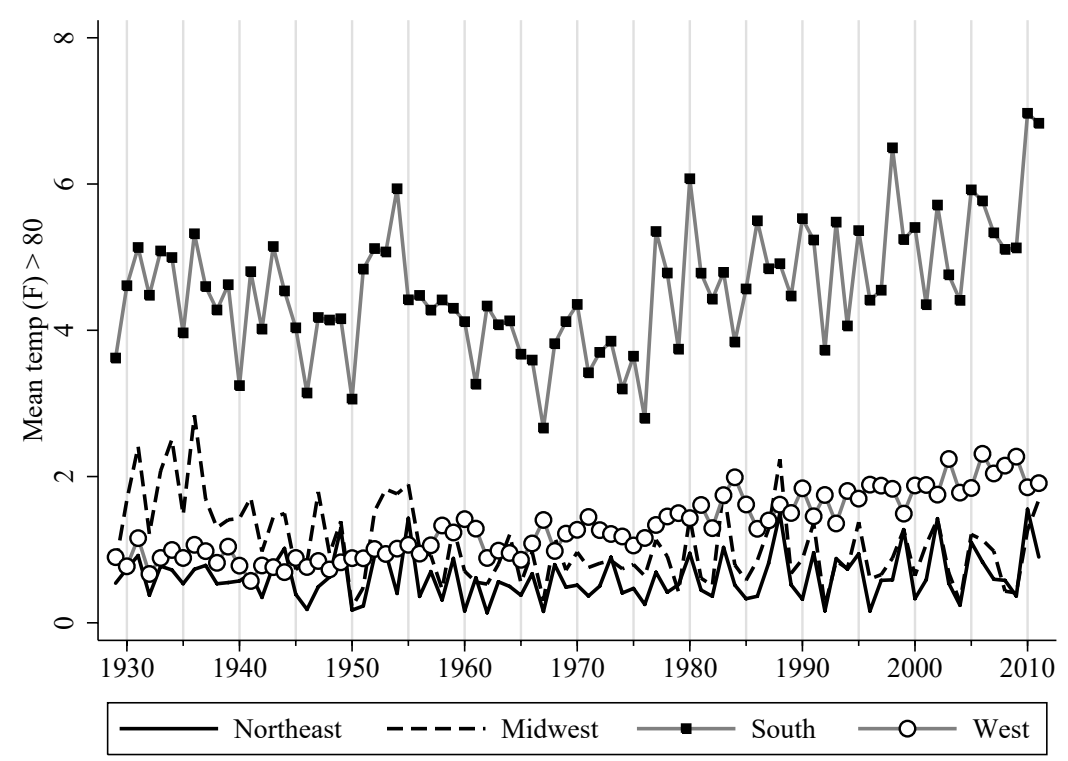

Note: Averages use state-year populations as weights. 
Figure A2: Estimated Temperature-Fertility Relationship: Effect of Daily Mean Temperature $<30{ }^{\circ} \mathrm{F}$ Relative to $60-70{ }^{\circ} \mathrm{F}$ on Log Birth Rate, by Months from Exposure

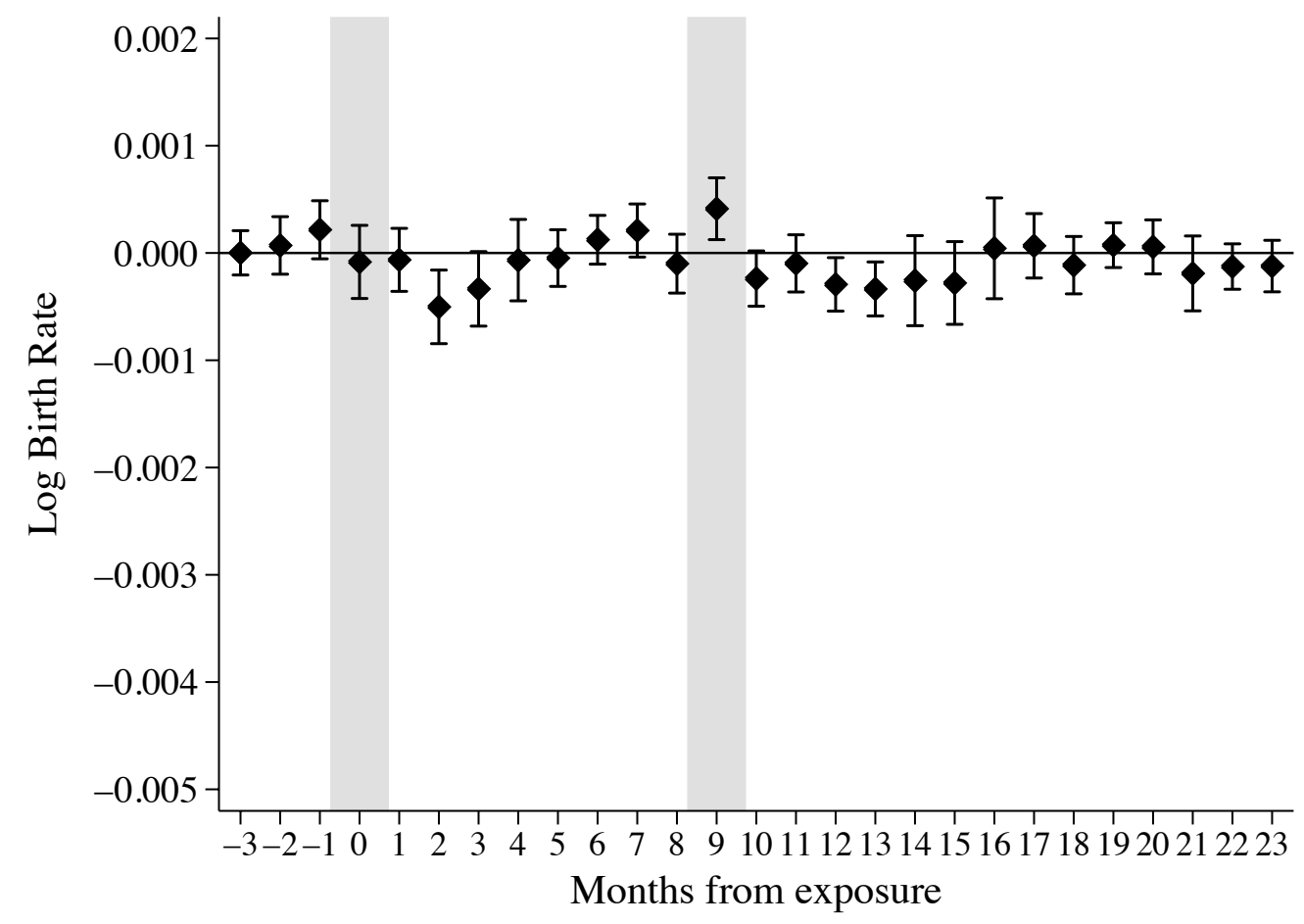

Note: See notes to Figure 3. 
Figure A3: Estimated Temperature-Fertility Relationship: Effect of Daily Mean Temperature $>80{ }^{\circ} \mathrm{F}$ Relative to 60-70 ${ }^{\circ} \mathrm{F}$ on Various Outcomes, by Months from Exposure

Panel A: Outcome is daily birth rate in levels

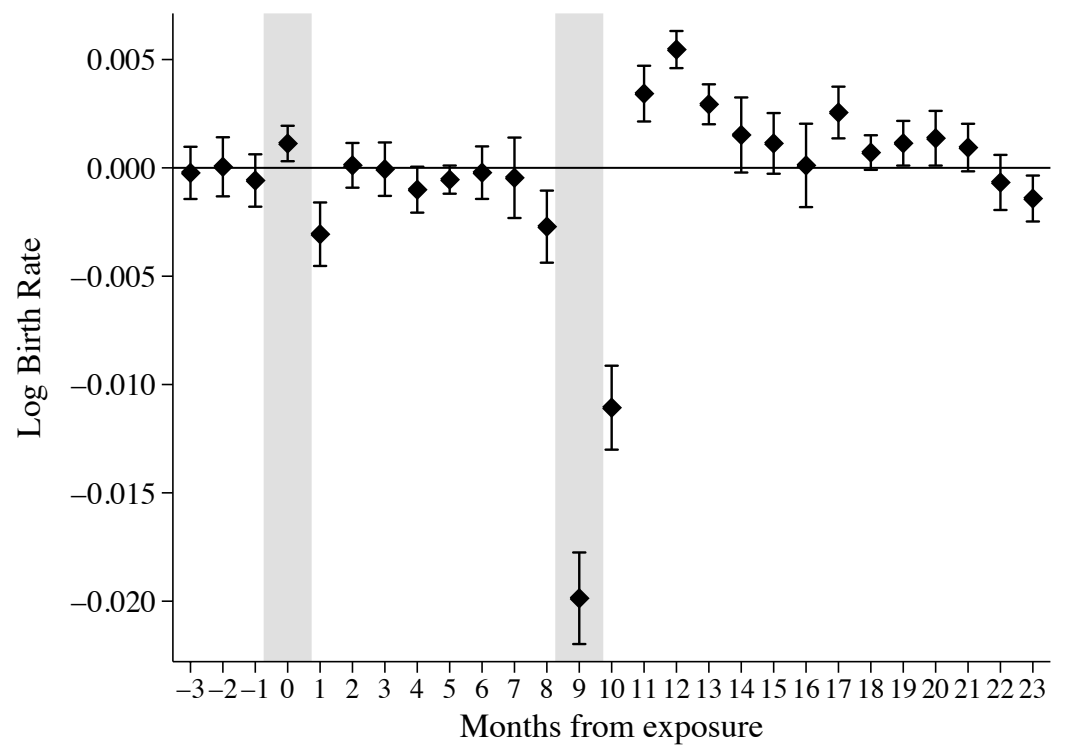

Panel B: Outcome is log of birth rate with female population 15-44 years old as denominator

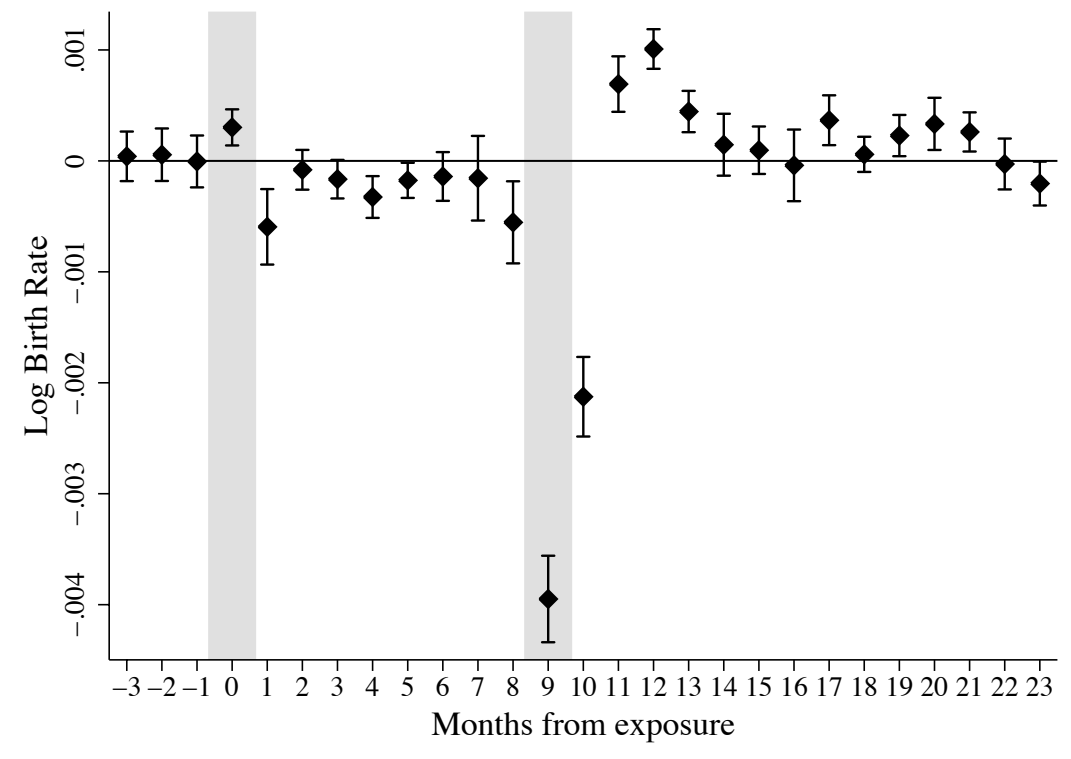

Note: See notes to Figure 3. The mean daily birth rate per 100,000 residents (population weighted) is 4.7 . 
Figure A4: Estimated Temperature-Fertility Relationship with Model that Includes $>90^{\circ} \mathrm{F}$ Bin

Panel A: Effect of daily mean temperatures on log birth rate 9 months later

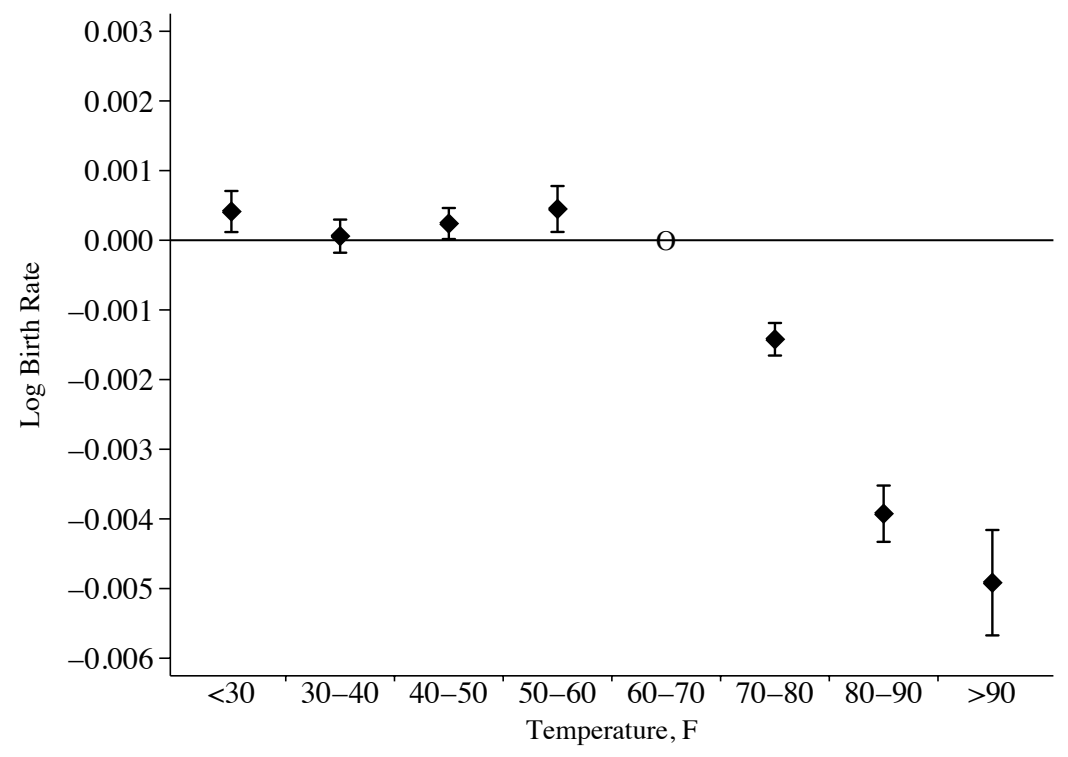

Panel B: Effect of daily mean temperature $>90^{\circ} \mathrm{F}$ relative to $60-70^{\circ} \mathrm{F}$ on log birth rate, by exposure month

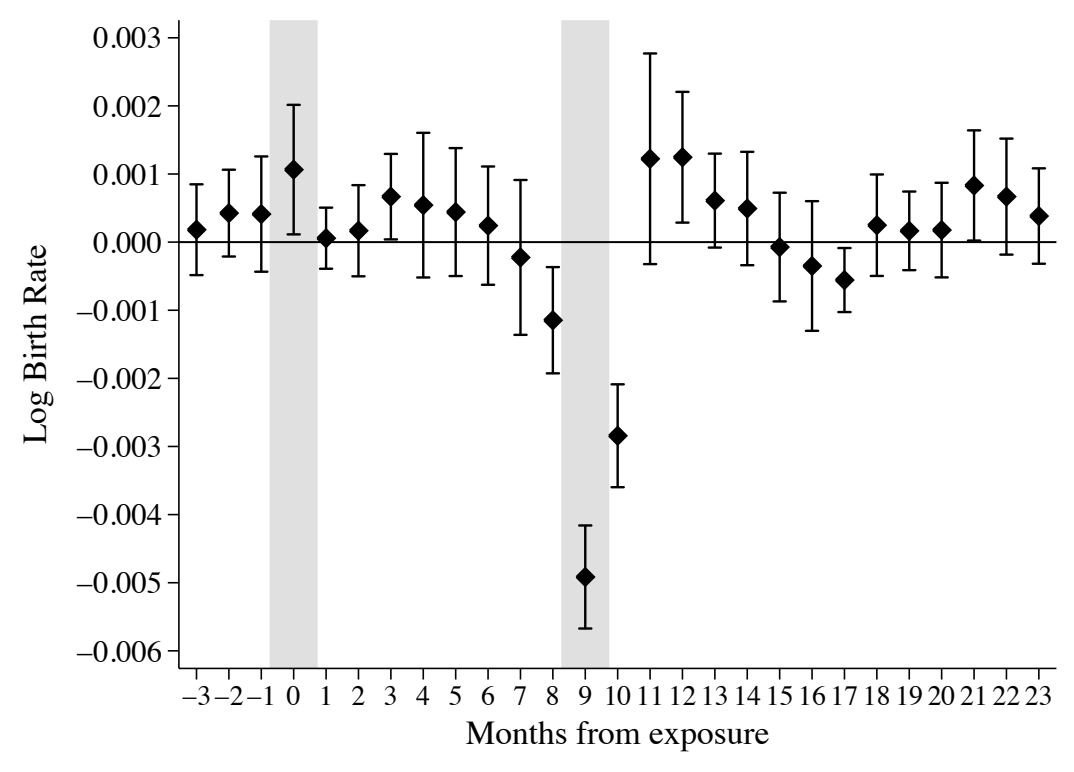

Note: See notes to Figure 3 for model controls. Here, the model uses temperature bins <30, 30-40, 40-50, 50-60, $70-80,80-90,>90^{\circ} \mathrm{F}$ with days between $60-70^{\circ} \mathrm{F}$ as the omitted category. 
Figure A5: Estimated Temperature-Fertility Relationship with Model that Includes $<20^{\circ} \mathrm{F}$ Bin

Panel A: Effect of daily mean temperatures on log birth rate 9 months later

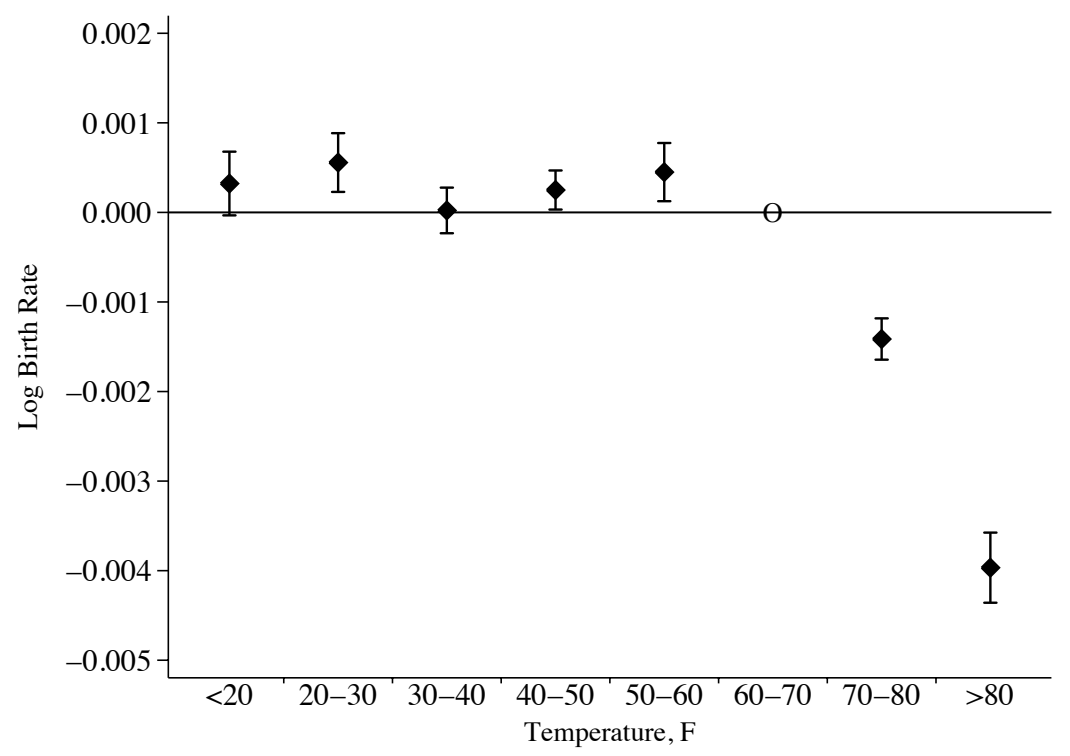

Panel B: Effect of daily mean temperature $<20^{\circ} \mathrm{F}$ relative to $60-70{ }^{\circ} \mathrm{F}$ on log birth rate, by exposure month

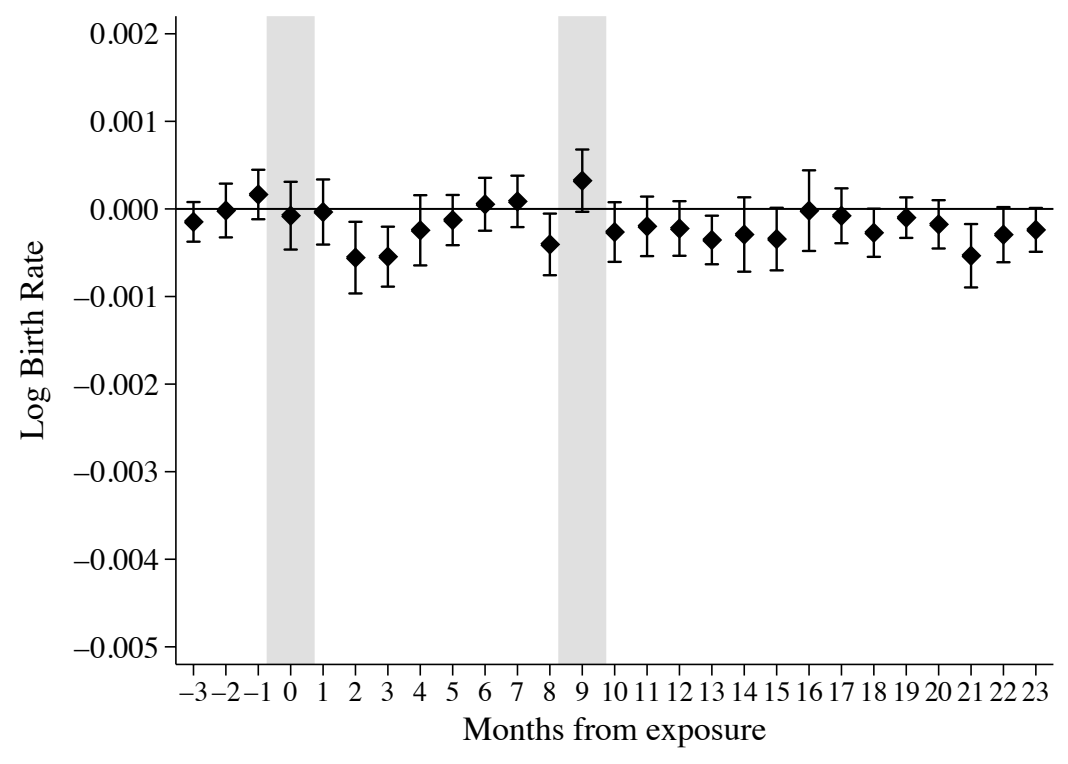

Note: See notes to Figure 3 for model controls. Here, the model uses temperature bins <20, 30-40, 40-50, 50-60, $70-80,>80^{\circ} \mathrm{F}$ with days between $60-70^{\circ} \mathrm{F}$ as the omitted category. 
Figure A6: Estimated Temperature-Fertility Relationship with Diurnal Temperature Bins

Panel A: Effect of 24 hours of diurnal temperatures on log birth rate 9 months later

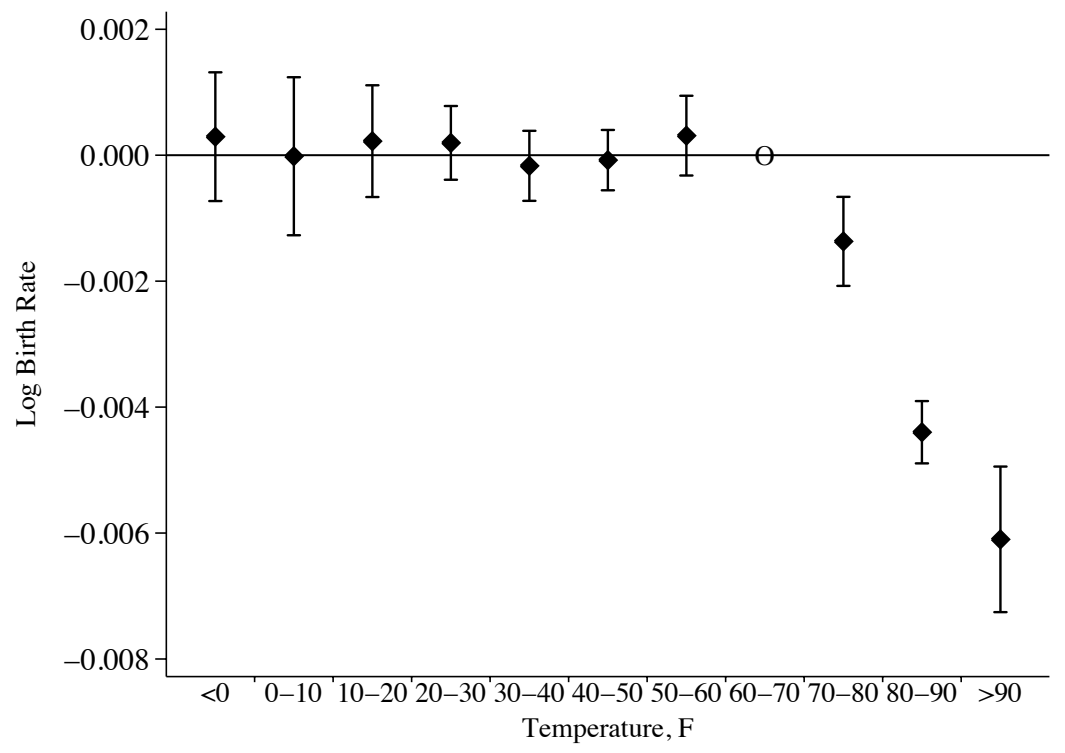

Panel B: Effect of 24 hours $>90{ }^{\circ} \mathrm{F}$ relative to $60-70{ }^{\circ} \mathrm{F}$ on log birth rate, by exposure month

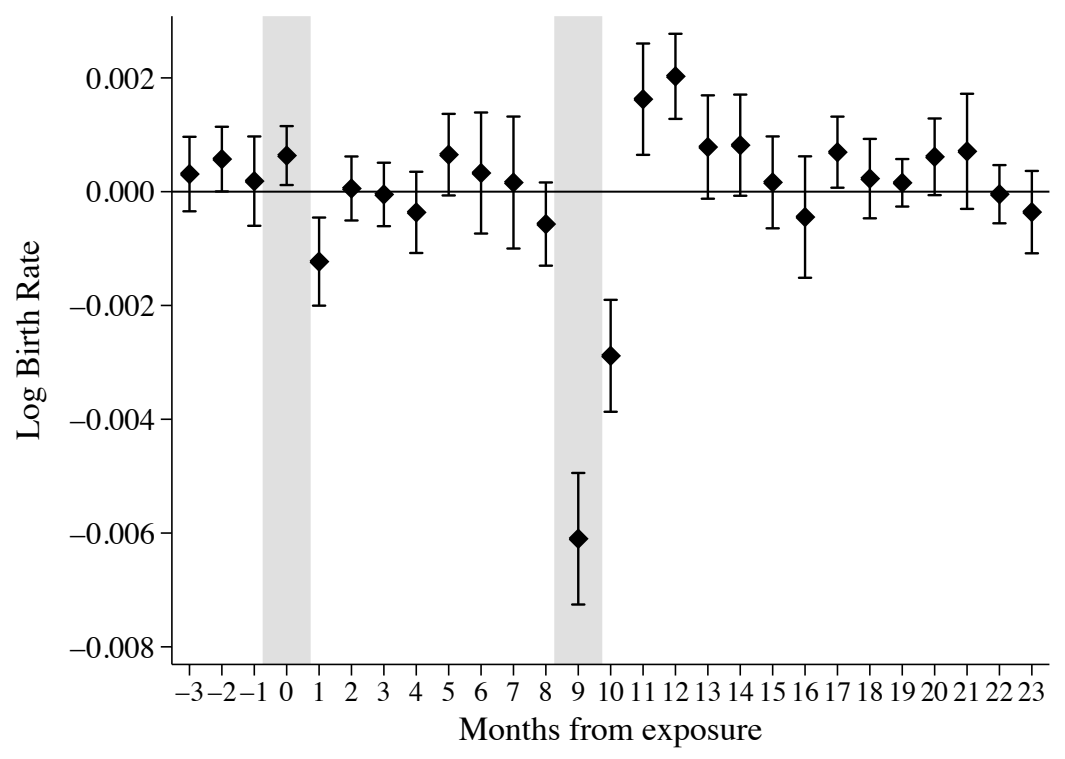

Note: See notes to Figure 3 for model controls. The estimates explore the effects of the proportion of the day in a $10^{\circ} \mathrm{F}$ interval, where diurnal temperatures are linearly interpolated from the daily maximum and daily minimum temperature. The bounds are set at $0 \mathrm{~F}$ and $90 \mathrm{~F}$. 
Figure A7: Estimated Temperature-Fertility Relationship with Temperature Spline Model

Panel A: Effect of daily mean temperatures on log birth rate 9 months later

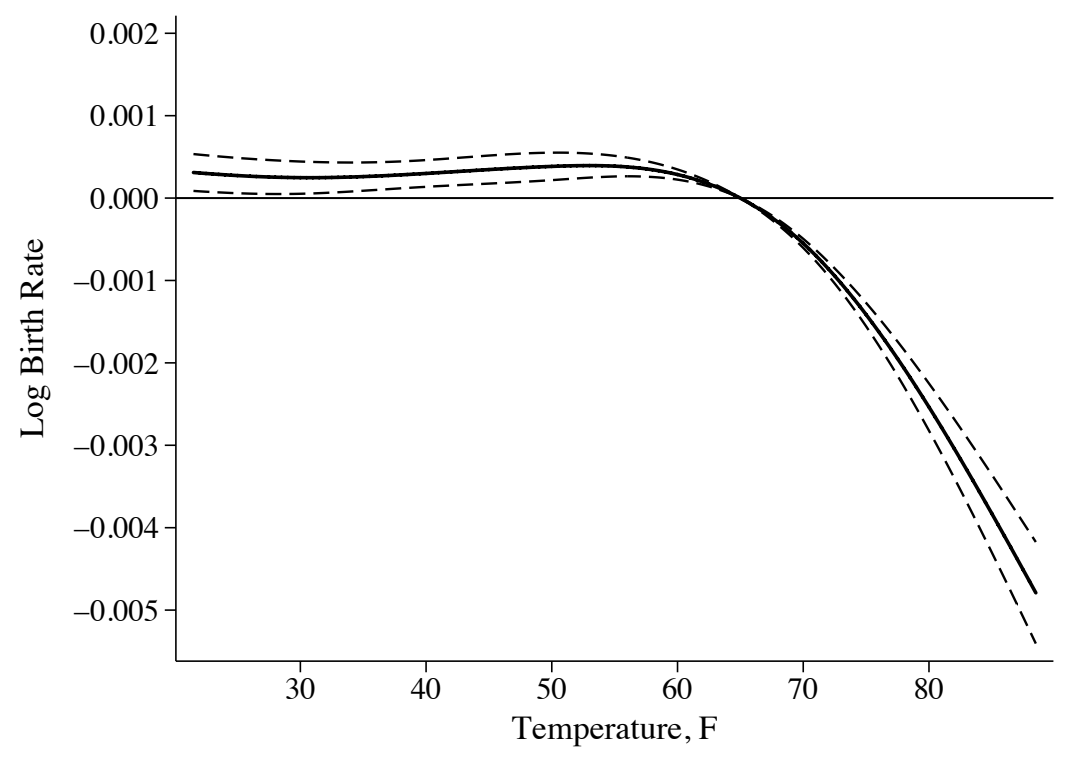

Panel B: Effect of daily mean temperature of $85^{\circ} \mathrm{F}$ relative to $65^{\circ} \mathrm{F}$ on log birth rate, by exposure month

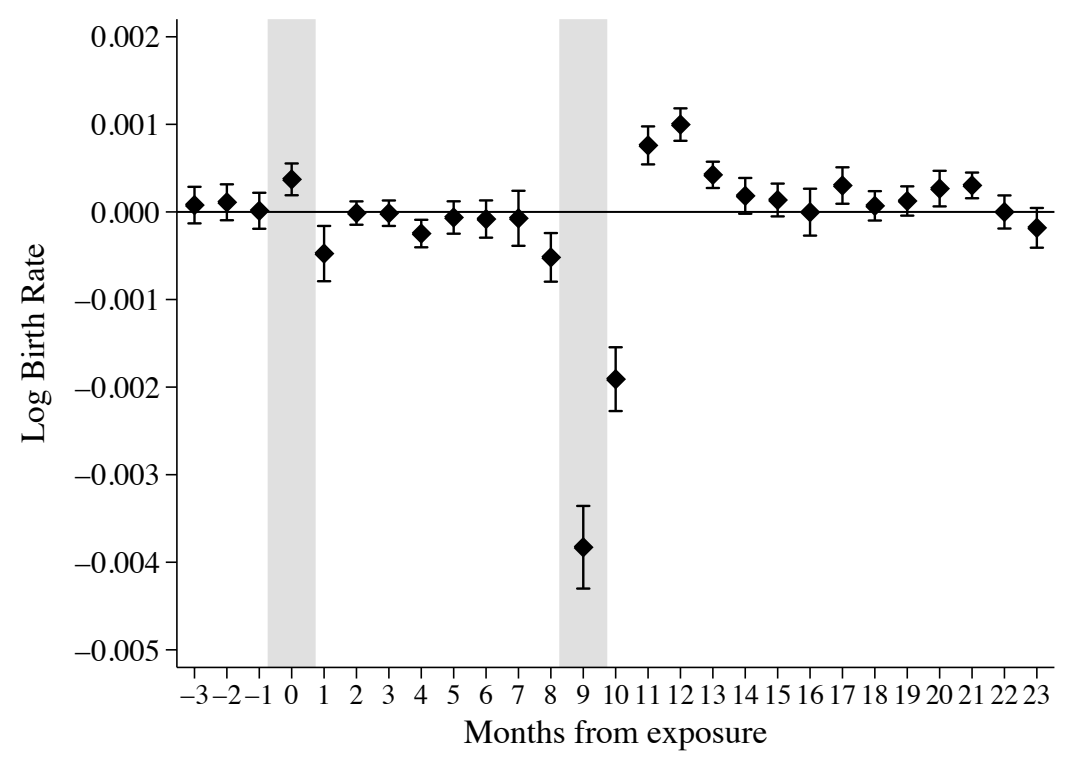

Note: See notes to Figure 3 for model controls. However, temperature is modeled as a cubic polynomial spline function with knots at daily mean temperatures of $10,30,40,70$, and $90^{\circ} \mathrm{F}$. 
Figure A8: Estimated Temperature-Fertility Relationship With Controls for Humidity, By Exposure Month

Panel A: Effect of daily mean temperature $>80^{\circ} \mathrm{F}$ relative to $60-70{ }^{\circ} \mathrm{F}$ on log birth rate

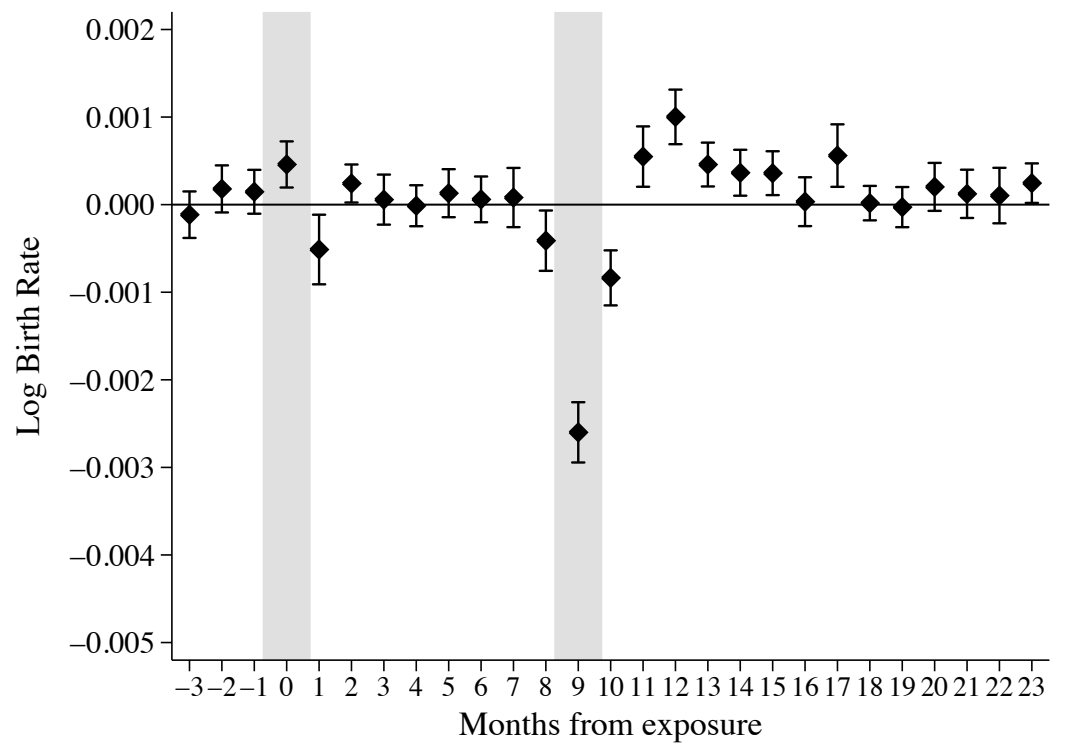

Panel B: Effect of daily mean specific humidity $>18 \mathrm{~g} / \mathrm{kg}$ relative to to $8-10 \mathrm{~g} / \mathrm{kg}$ on log birth rate

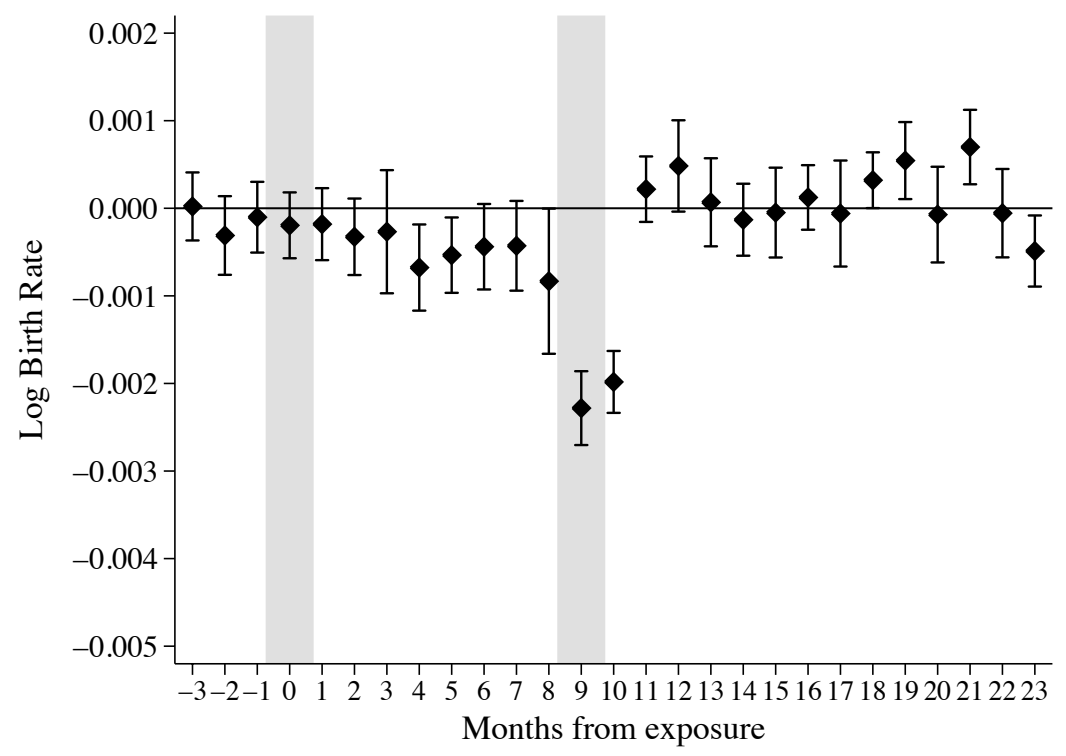

Note: See Figure 3 for model controls. Humidity is measured in terms of water vapor per kilogram of air $(\mathrm{g} / \mathrm{kg})$, Humidity is modeled in $2 \mathrm{~g} / \mathrm{kg}$ bins with $>18$ grams as the upper category and 8-10 grams as the omitted category. Due to data limitations with the humidity variable, the sample is restricted to the $1945-2010$ period. Humidity levels were $>18 \mathrm{~g} / \mathrm{kg}$ approximately 3 days per year in our sample. 
Figure A9: Estimated Temperature-Fertility Relationship with Model that Excludes State-Year Fixed Effects Panel A: Effect of daily mean temperatures on log birth rate 9 months later

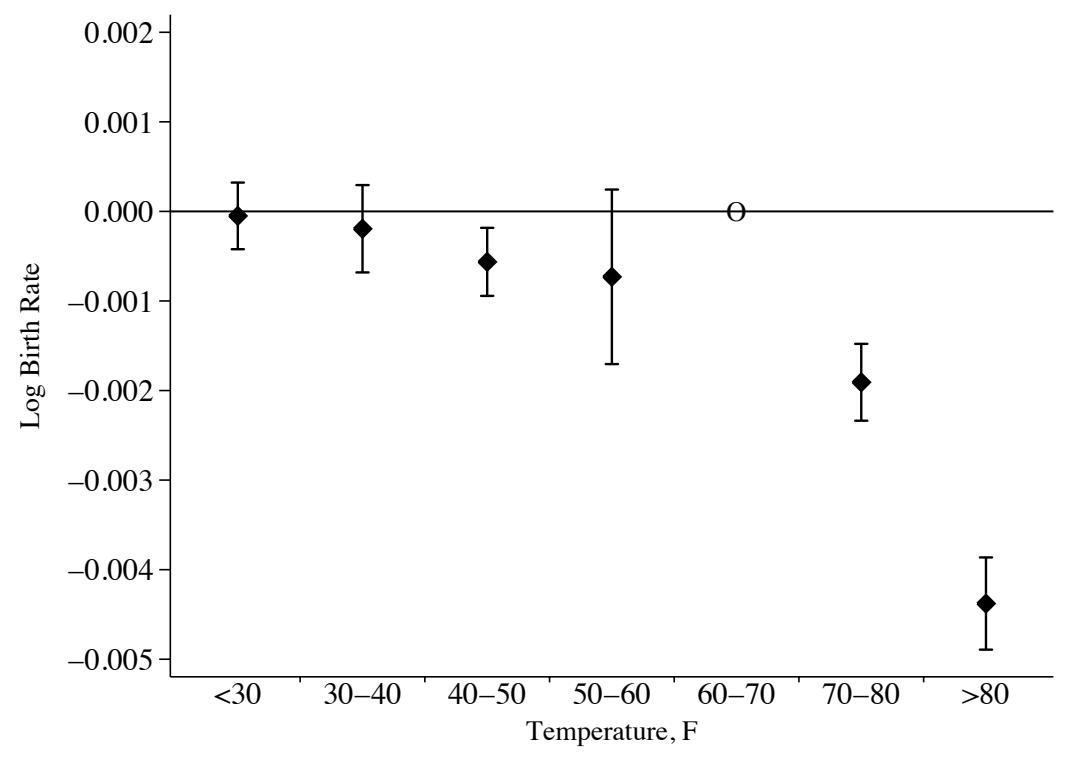

Panel B: Effect of daily mean temperature $>80{ }^{\circ} \mathrm{F}$ relative to $60-70{ }^{\circ} \mathrm{F}$ on log birth rate, by exposure month

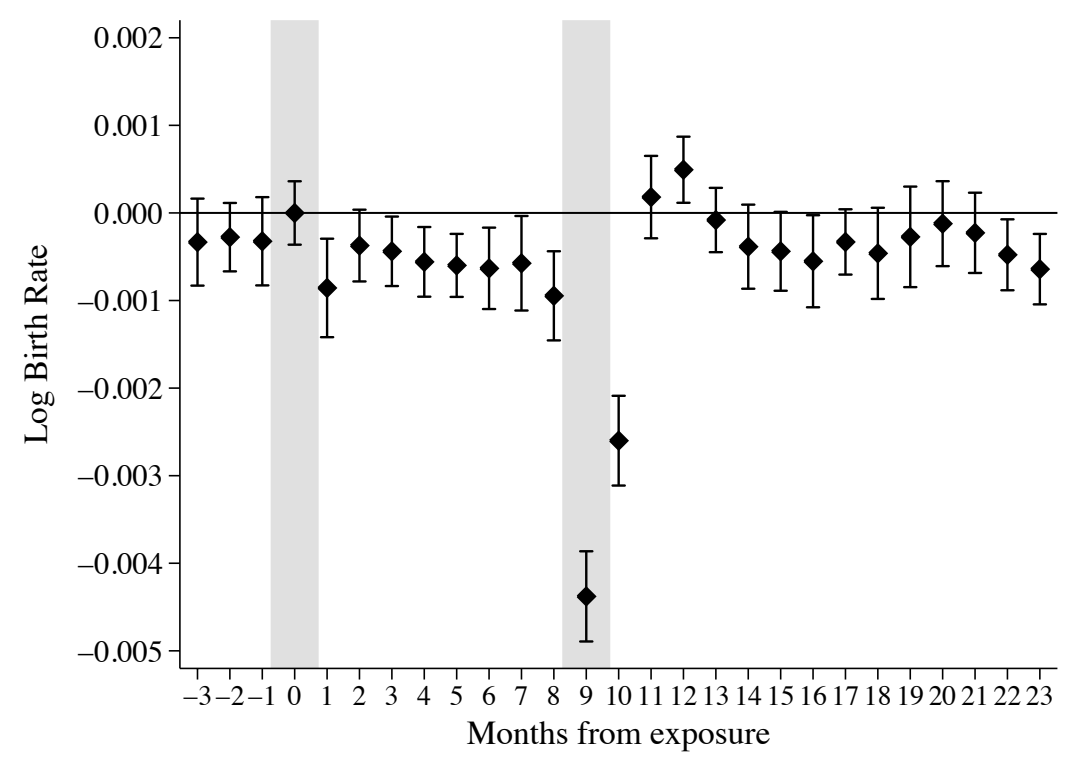

Note: See notes to Figure 3 on the temperature and precipitation controls. The model here has year-month fixed effects, state-by-calendar-month fixed effects, and state-by-calendar month quadratic time trends, but no state-by-year fixed effects. 
Figure A10: Average Annual Number of Days $>80^{\circ} \mathrm{F}$, Absolute Regression Adjusted Errors

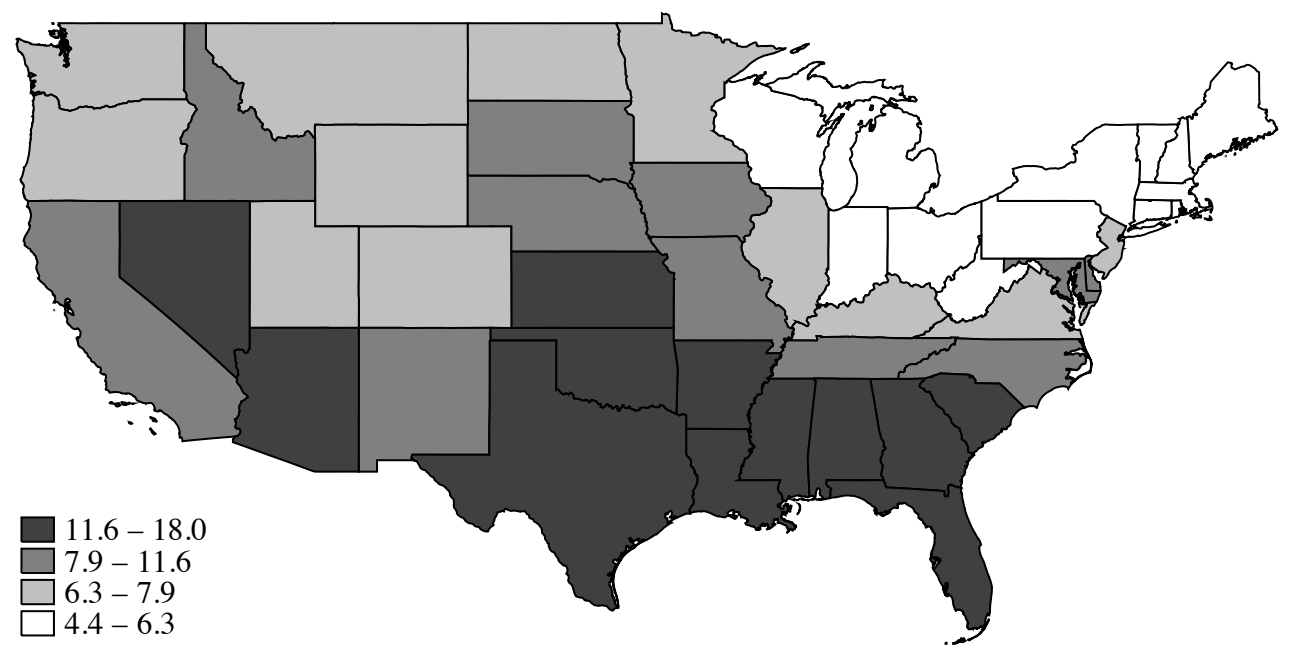

Note: This map illustrates the average absolute error from a regression including year-month fixed effects, stateby-calendar-month fixed effects, state-by-calendar month quadratic time trends, and state-year fixed effects. The regression uses state-year populations as weights. 
Figure A11: Average Low Birth Weight and Daily Mean Temperatures $>80^{\circ} \mathrm{F}$, By Calendar Month Panel A: Low birth weight ( $<2,500$ grams)

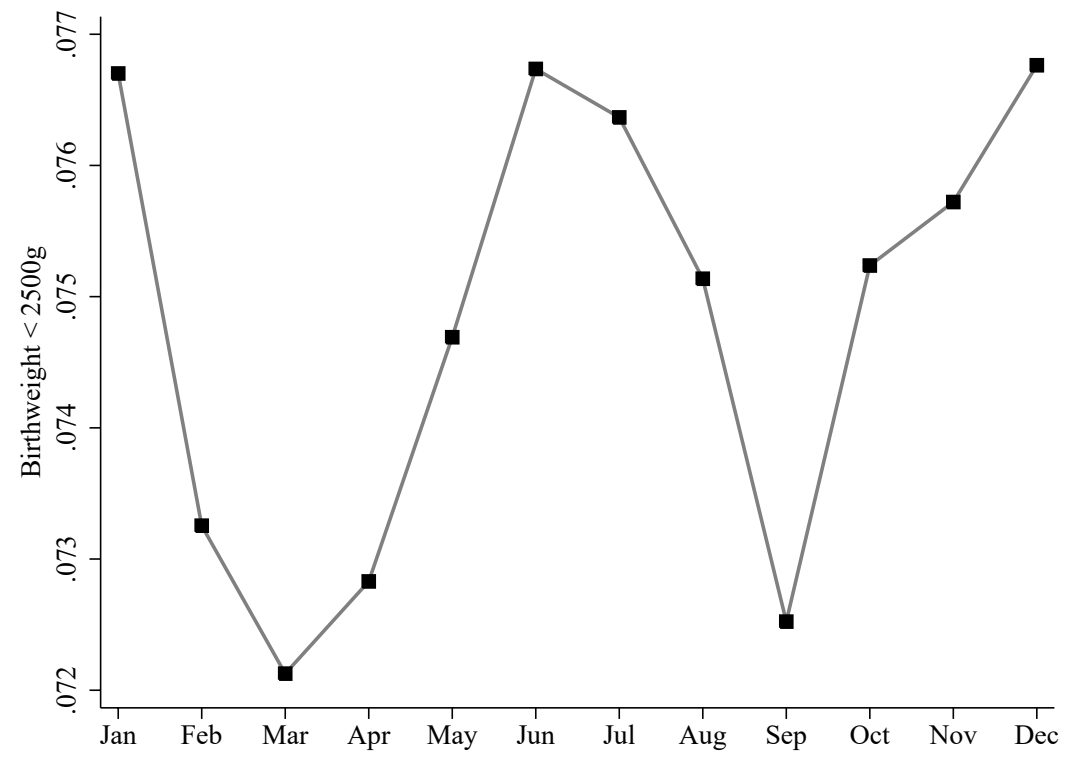

Panel B: Days with daily mean temperature $>80^{\circ} \mathrm{F}$

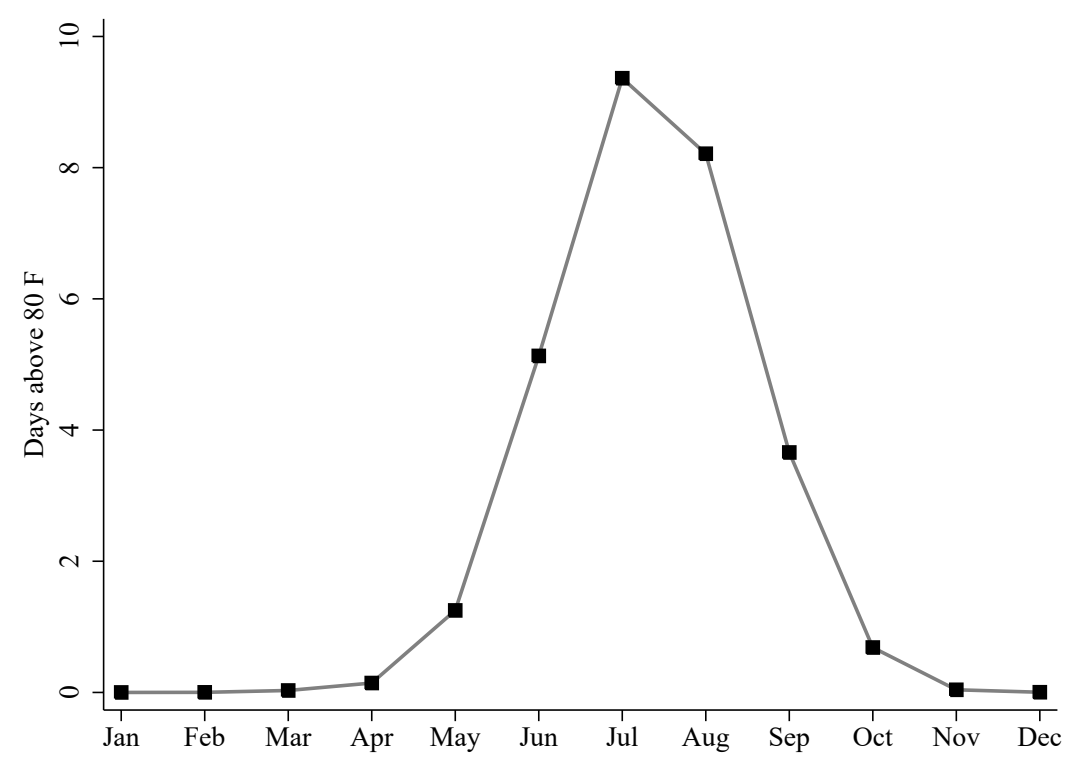

Note: These data represent the means from the 1968-2010 period since birth weight data are only available starting in 1968. Calculations use state-year population weights. 
Figure A12: Residential Population with Air Conditioning

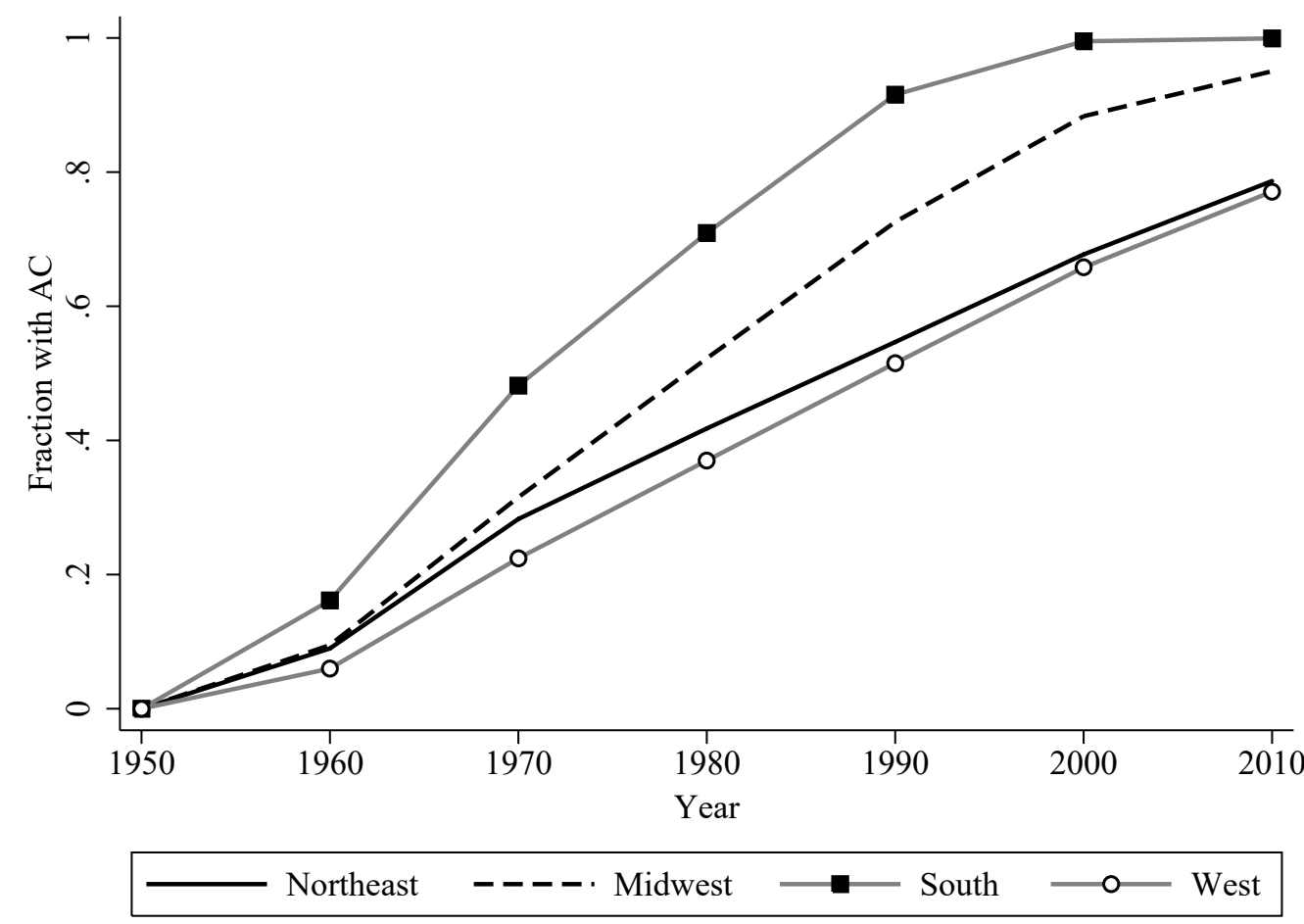

Note: Air conditioning coverage is the fraction of the population in the respective Decennial Census that had at least one air conditioning unit or central air conditioning. The calculations linearly interpolate coverage using the 1960, 1970, and 1980 Census and assuming no coverage as of 1950. 
Figure A13: Climate Change Temperature Projections from Error-Corrected Hadley CM3 A1FI

Panel A: Changes in daily mean temperatures per year

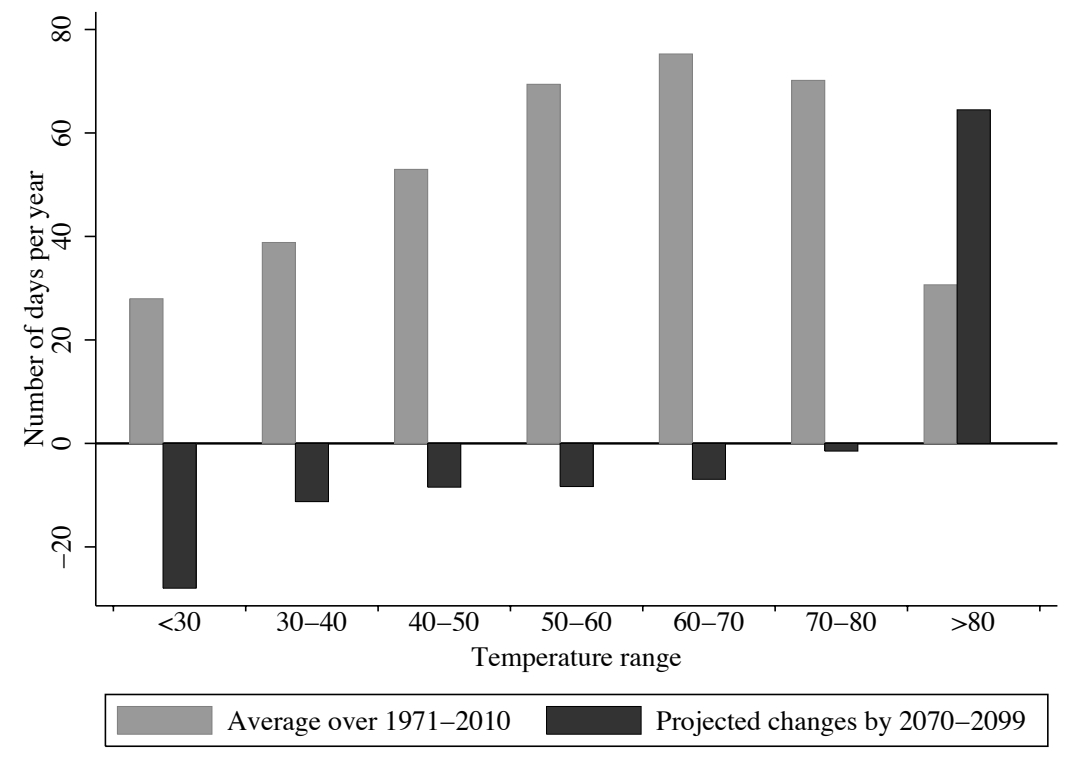

Panel B: Change in daily mean temperature $>80^{\circ} \mathrm{F}$, by calendar month

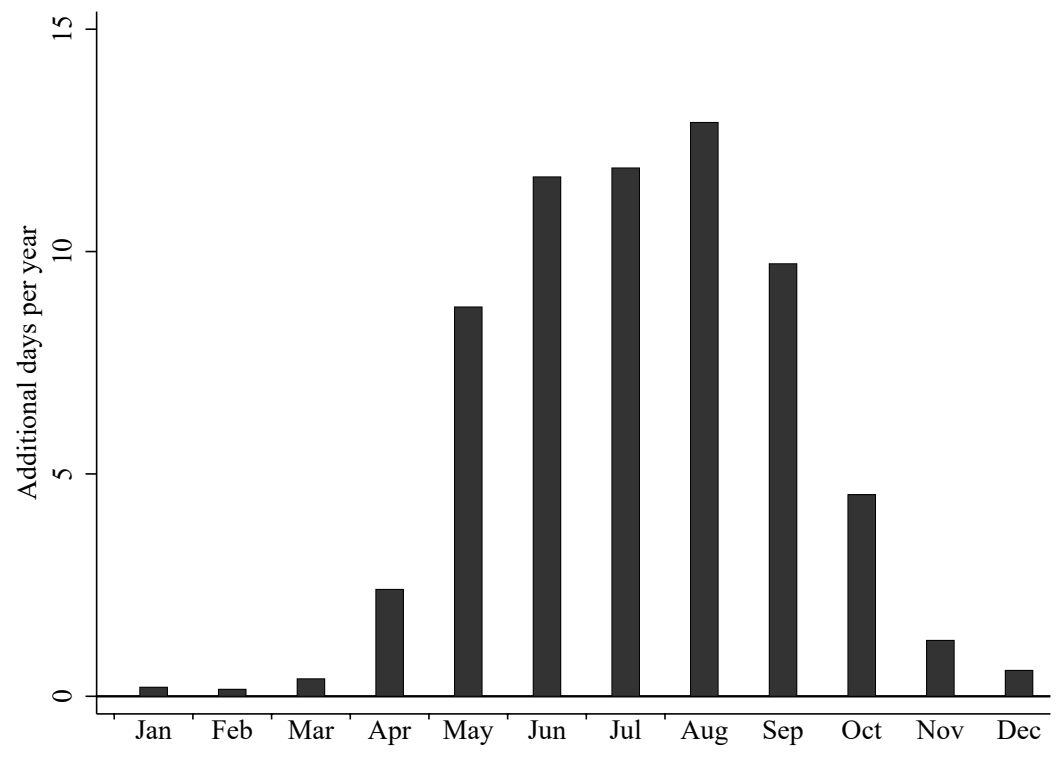

Note: Estimated using county population estimates in 2000 as weights. The changes reflect the differences between the 1990-2002 and 2070-2099 periods. These error-adjusted climate projections factor out the difference between the realized temperatures and model predictions at during the 1990-2002 period. 
As an additional test of the importance of socioeconomic status, we estimate whether exposure to high temperatures correlate with selected maternal characteristics found in the post-1968 Natality data. All the model controls are identical to our core model (equation 1), except we restrict the model to exposure months 0 through 13 in order to improve statistical power and facilitate exposition of the results. We focus on the effects of days above $>80{ }^{\circ} \mathrm{F}$, though our model controls for other temperature bins. Appendix Table B1 (below) presents the marginal effect of one additional $>80^{\circ} \mathrm{F}$ day across months 0 through 13 where the outcome is an indicator for a particular maternal characteristic reported on the birth certificate. One hypothesis is that the observed decline in births in months 8-10, and subsequent rebound in months 11-13, is comprised of relatively more low SES mothers. To test this hypothesis, we have chosen outcomes that reflect lower socioeconomic status (SES), including: mother has less than high school education, maternal age 15-19, mother is non-white, and father's "information" (i.e. age) is missing from birth certificate, a proxy for paternal support. Detection of statistically significant negative coefficients in months 8-10 would provide support for low SES mothers being more vulnerable to temperature shocks. Any differences in months 11-13 could imply an explicit dampening of the rebound, or simply reflect a selection away from women who are likely to attempt to conceive in the months following a temperature shock.

Overall, Appendix Table B1 estimates provide evidence that low SES mothers are less likely to conceive following exposure to high temperatures. Though, the effect sizes are generally small. For example, the month 9 coefficient indicates one $>80^{\circ} \mathrm{F}$ day leads to a statistically significant 0.022 percentage point decline in the probability the mother has less than a high school education (as opposed to having a high school degree or more). We find similarly negative and statistically significant effects for an indicator of 'mother is non-white' and 'father's information missing'. We detect no statistically significant relationship with births to young mothers (ages 15-19). There is some, albeit less conclusive, evidence to support the hypothesis that the rebound is comprised disproportionately of low SES mothers. Only the point estimates on 'mother is non-white' are positive and statistically significant in months 11-13.

Our findings regarding maternal characteristics are somewhat different, though not in conflict, with recent work by Buckles and Hungerman (2013) (hereafter BH). BH explored the role of maternal selection in differences in outcomes across season of birth. They conclude weather at the time of birth, as opposed to weather at conception, is a better predictor of seasonality in maternal characteristics. To test their hypothesis, they make the assumption that weather 12 months prior to birth is a good proxy for expected weather at birth. Conversely, our analysis suggests the weather 12 months prior is likely related to births through a shift in conceptions due to high temperatures. BH's weather controls include average monthly minimum temperature, average monthly maximum temperature, days in the month above 90 ${ }^{\circ} \mathrm{F}$, and degree departure from normal temperature. BH show that weather 12 months prior to birth is a stronger predictor of seasonal maternal characteristics than weather 9 months prior. Conversely, our model predicts very little variation in maternal characteristics at month 9 , and even less at month 12 . That said, our model is identified by random fluctuations in monthly temperatures, unlike $\mathrm{BH}$ whose model is partially identified from some fixed differences in seasonality across counties. (BH's model does not control for county-by-month fixed effects, so the estimates include fixed differences in seasonality.) While our model can explain a substantial portion of the seasonal variation in birth rates, the remaining variation may still be driven by expected weather conditions and a mechanism consistent with what $\mathrm{BH}$ propose.

Appendix Table B1 also reports the effect of $>80^{\circ} \mathrm{F}$ days on the probability that a recorded birth is a "first live birth". As mentioned above, one potential explanation for the large reduction in births at month 10 (relative to month 9 ) is that temperature exposure disproportionately reduces conception probabilities among first-time mothers, who typically have longer gestational lengths. A detection of a negative and statistically significant coefficient at month 10 would support this hypothesis. The coefficient is negative, but statistically insignificant, so support for this hypothesis is limited. 
To test for fetal selection, Appendix Table B1 includes regression estimates with probability of female birth as the outcome. Prior research shows that male fetuses are more vulnerable to in utero health shocks (Trivers Willard, 1973; Sanders and Stoecker, 2015). We do not observe any statistically significant impacts between months 2 through 10. However, we do find a large and statistically significant increase in probability of female birth in month 1 and a large, but not statistically significant, decrease in females in month 0 . These estimates suggest that the displacement in births between months 0 and 1 and/or fetal deaths in month 1 are likely driven by male fetuses. Relatedly, Appendix Table B1 estimates whether temperature shocks correlate with shorter gestational lengths in month 0 , but longer gestational lengths at month 1; the estimates are imprecise so we cannot draw meaningful conclusions. Note that information on gestational length is limited in the Natality data prior to 1981 . For example, gestational length is missing in $40 \%$ of births in $1969,22 \%$ in 1980 , but only $6 \% 1981$.

We also explore the effect of $>80^{\circ} \mathrm{F}$ days on the probability of low birth weight in Appendix Table B1, though our present discussion focuses on the possibility of selection on healthier infants in months 8-13 and not on the causal impact of in utero exposure during months 0-7. We observe lower risk of low birth weight in month 8. Specifically, each $>80^{\circ} \mathrm{F}$ day leads to a 0.008 percentage point (or $0.1 \%$ ) decline in the probability of low birth weight 8 months later. Taken with the decline in birth rates at month 8 , this improved health could be either fetal losses among unhealthier fetuses or a selection effect at conception among births of 8-month gestational lengths. Unlike the effect at month 8, extreme heat correlates with an increase in low birth weight in months 9 and 10 . For example, each $>80$ ${ }^{\circ} \mathrm{F}$ day increases low birth weight risk by 0.008 percentage points (or 11\%) 9 months later. The lower birth weight in months 9 and 10 could be a lasting causal impact on fetal health or a selection effect. Though we cannot definitively differentiate between the two, the analysis of maternal characteristics suggest that, if anything, birth outcomes should improve in months 9 and 10. The fact that we observe worse outcomes supports to the possibility of a causal health impact.

We also observe a statistically significant 0.009 percentage point increase in low birth weight risk from exposure in the month of birth. In the two months leading up to the month of birth, the estimates are also positive, but smaller and statistically insignificant. Given we do not observe a large negative coefficient in month 1 , we can rule out the possibility of forward displacement with unhealthier infants (and not shorter gestations, per se). In the interest of conciseness, we must leave further exploration into the in utero impacts to future work.See Deschenes et al. (2009) for more discussion on the impacts of temperature on birth weight. 


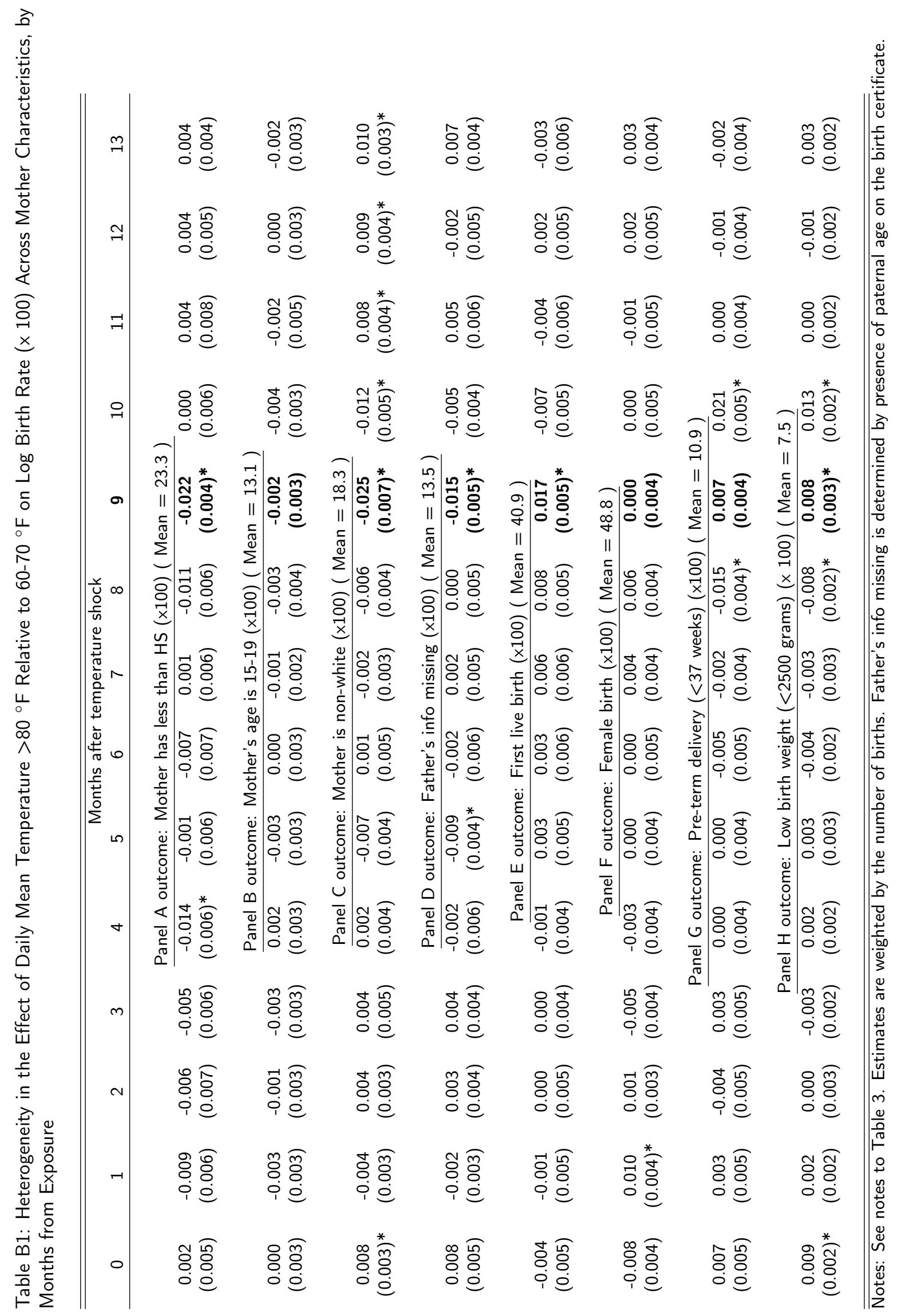

